\title{
Strength of submarine hoses in Chinese-lantern configuration from hydrodynamic loads on CALM buoy
}

\author{
Chiemela Victor Amaechi ${ }^{1,3}$, Facheng Wang ${ }^{2, *}$, Xiaonan Hou ${ }^{1}$, Jianqiao Ye ${ }^{1, *}$ \\ ${ }^{1}$ Engineering Department, Lancaster University, Lancaster, LA1 4YR, UK. \\ ${ }^{2}$ Department of Civil Engineering, Tsinghua University, Beijing 100084, PR China. \\ ${ }^{3}$ Standards Organisation of Nigeria (SON), 52 Lome Crescent, Abuja, Nigeria.
}

\begin{abstract}
Catenary Anchor Leg Moorings (CALM) buoys are offshore structures that have been used for offloading, loading and discharge purposes. In this study, dynamic analysis is carried out on the submarine hoses attached to a CALM buoy and moored by six mooring lines in a water depth of $23.0 \mathrm{~m}$. Two submarine hose-strings in Chinese-lantern configuration are attached underneath the buoy. Three environmental conditions are considered, representing West Africa Sea, North Sea and Gulf of Mexico (GoM), respectively. Hydrodynamic simulation using ANSYS AQWA is first conducted to determine response amplitude operators (RAOs) of the buoy. Coupled dynamic models, where both buoys and hoses are included, are developed using Orcaflex. Parametric studies are conducted to investigate the effects of hose hydrodynamic loads and flow angles on the structural behaviour of the hoses, including bending moments, effective tension and minimum bend radius. From the study, a guidance dynamic amplitude factor of 2.0 considering hydrodynamic loads on hose $D A F_{\text {hose }}$ is proposed.
\end{abstract}

Keywords: Hydrodynamic Load; Chinese-Lantern Configuration; Submarine Hose; CALM Buoy; Dynamic Amplification Factor; Composite Riser; Strength
Abbreviations
$\rho$ - Density of water
$\omega$ - Angular frequency
$\omega_{p}$ - Peak angular frequency
$\gamma$-Peak enhancement factor
$\eta$ - The incident wave amplitude
$\lambda$ - Wavelength
$\theta$ - Angle to the horizontal axis
$3 D$ - Three Dimensional
A - Area of the body
ABS - American Bureau of Shipping
CALM - Catenary Anchor Leg Mooring
$C_{d}$ - drag coefficient
$C_{m}$-Inertial force coefficient
$\mathrm{CoG}-$ Centre of Gravity
DAF - Dynamic Amplification Factor
$D A F_{\text {hose - Dynamic Amplification Factor of Hose }}$
DNVGL - Det Norkse Veritas \& Germanischer Lloyd
FE- Finite Element
FPSO - Floating, Production, Storage and Offloading
$g$ - Gravitational constant
GoM - Gulf of Mexico
GMPHOM - Guide to Manufacturing and Purchasing
Hoses for Offshore Moorings
$H_{s}$ - Significant wave height
Hose 1 - Leeside Submarine Hose-String 1
Hose 2 - Weatherside Submarine Hose-String 2
Project 1,2 \& 3 -Different Environmental Case Studies

\author{
ID - Inner Diameter \\ JONSWAP - Joint North Sea Wave Project \\ MBR - Minimum Bend Radii \\ MWL - Mean Water Level \\ OCIMF - Oil Companies International Marine Forum \\ OD - Outer Diameters \\ OLL-Offloading Lines \\ PLEM - Pipeline End Manifold \\ QTF - Quadratic Transfer Function \\ RAO - Response Amplitude Operators \\ $s-$ Arc length \\ SPM - Single Point Mooring \\ $T_{h}-$ Horizontal tension force \\ $T_{v}$ - Vertical tension force \\ $T_{z}$ - Zero crossing period \\ $V$ - Volume of the body \\ W- Weight of the body \\ $w_{s}$ - Submerged weight \\ $x$ - Section length of the mooring line \\ $z$ - Height above seabed \\ $\left\{\boldsymbol{F}_{h}\right\}$ is the hydrodynamic force vector for the system \\ [M] is the mass matrix \\ $[\boldsymbol{C}]$ is the damping matrix \\ $[K]$ is the stiffness matrix \\ $\{\boldsymbol{x}\}$ is the motion vector \\ $\{\dot{x}\}$ is the velocity vector \\ $\{\ddot{\boldsymbol{x}}\}$ is the acceleration vector
}

*Correspondence authors: j.ye2@lancaster.ac.uk (J.Ye); wangfacheng@tsinghua.edu.cn (F.Wang) 


\subsection{Introduction}

Catenary Anchor Leg Mooring (CALM) system is one of the most popular systems adopted by the offshore applications, where flexible risers have been used in most cases. With recent development on the design and production of offshore hoses, there is an increase in the application of CALM systems. Despite the cost-effectiveness of hoses and easier installation, the challenges with hoses are the short service period due to their limited flexibilities and low fatigue resistance. Thus, hoses are very suitable on platforms that require short service periods and less cost in production. Generally, CALM buoy hose systems can be in either Lazy-S, Steep-S or Chinese-Lantern configurations (Trelleborg 2016; Bluewater 2009; Yokohama 2016; EMSTEC 2016). The performance of CALM buoy hose systems in waves are governed by three main components, namely the viscous force components, non-viscous force components and the coupling effect between the line dynamics and the motion of the CALM buoy. The viscous effects include the line viscous forces and the viscous damping forces acting on the CALM buoy. The non-viscous effects include the inertia forces, hydrostatic forces, line inertia forces, line static forces, added mass, potential damping from radiated wave forces and wave excited forces. The dynamic structural behaviour can be studied by using Orcaflex, as done for the pipeline installation (Wang et al. 2017; Wang 2018; Wang \& Han 2019), riser designs (Amaechi \& Ye, 2017; Amaechi et al., 2018) and other floating structures like Paired-Column Submersibles (Odijie, et al., 2017(a); Odijie, et al., 2017(b)). General applications include offloading hoses connecting the buoy to tankers and loading hoses transferring oil from loading towers.

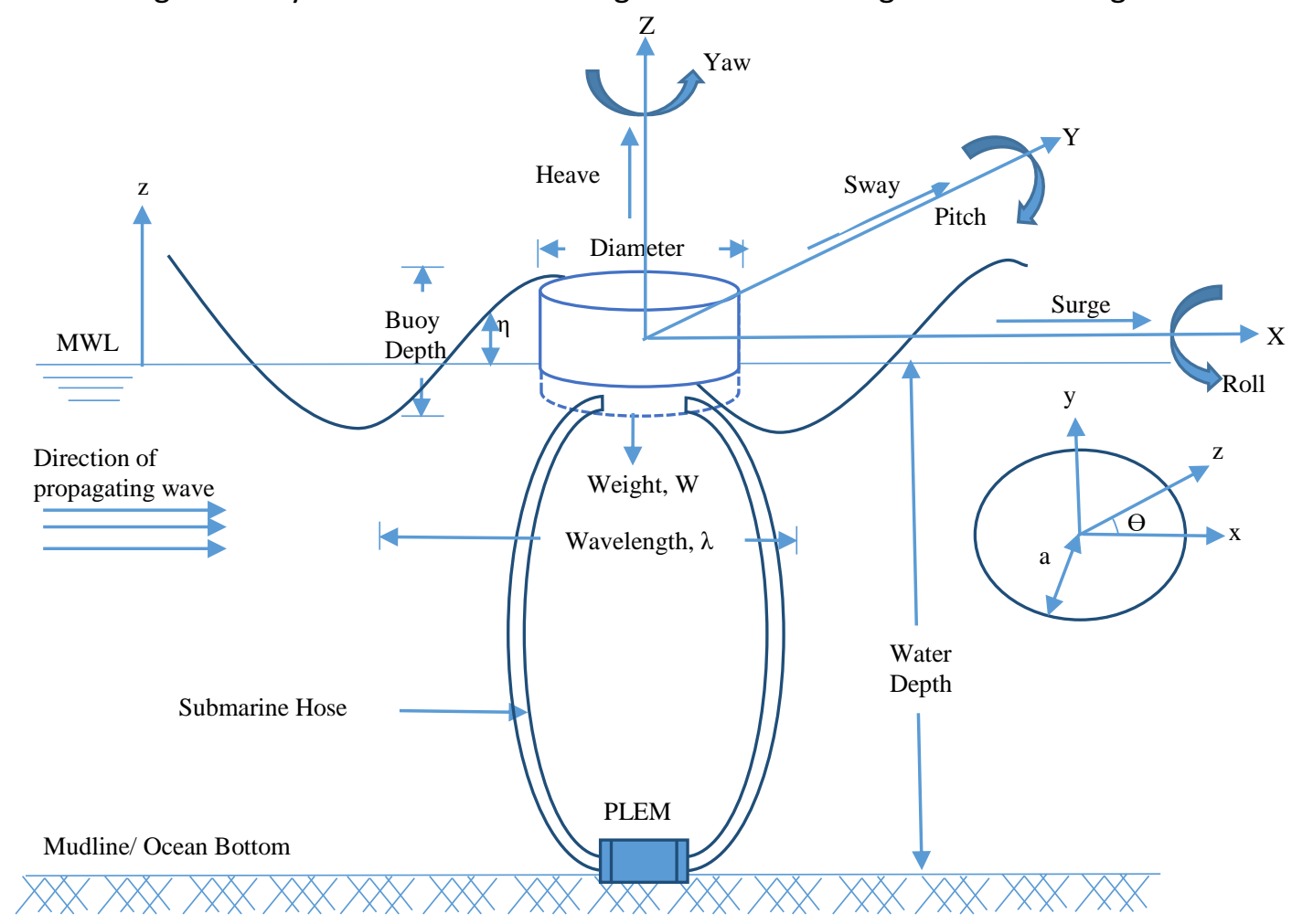

Figure 1 Sketch of wave forces on a CALM Buoy submarine hoses in Chinese-Lantern configuration

Although hoses have been extensively used in the industry, detailed investigations on the dynamic structural behaviour of a hose system integrated in CALM are somehow limited. For instance, though it is well known that hoses are susceptible to the motions of the connected CALM buoy (Sun et al. 2015; 
Wichers 2013), the influence of buoy motion on the hose behaviour has not been studied quantitatively in terms of full loading history, fatigue, minimum bending radius (MBR) and effective tensions. Figure 1 is a definition sketch of wave forces on a CALM Buoy in a Chinese Lantern configuration, showing the submarine hoses. The buoy has 6 degrees of freedom, and floats on the water body along its waterline. A typical application of it is the Shell's Malampaya CALM buoy, as shown in Figure 2. CALM buoys are generally moored using single point mooring (SPM) systems. Therefore, the motion of the buoy can be significantly large and may significantly affect the dynamic behaviours of the hoses. It is difficult to couple a CALM buoy and hoses in dynamic analysis due to the difficulties in determining hydrodynamic coefficients of buoy, submarine hoses and mooring lines (Sagrilo et al. 2002; Santala \& Wang 2016). With the first integral floating hose system being installed in 1969 by Esso at Marsa El Brega (Ziccardi \& Robbins 1970), researchers started studying the behaviour of the system accordingly. Brady et al. (1974) investigated the forces on the hoses of a mono-buoy using a statistical method for the environmental data, which led to more studies on single point moorings and offloading systems using hoses attached to CALM buoys. However, there are still challenges with damping calculation, resulting in that some procedures are proposed. These include quadratic drag linearization ( Salem et al. 2012), quadratic relative velocity (Berhault et al. 2004), quadratic absolute velocity (Cozijn \& Bunnik 2004) and some other formulations using Morison Equation (Morison et al. 1950; Brebbia \& Walker 1979; Chandrasekaran 2015; Sarpkaya 2014). In this respect, more attention has been focused on CALM buoys than on hoses (Cozijn et al. 2005; Roveri et al. 2002; Wang \& Sun 2015). Considering validations, there are challenges in model tests and corresponding numerical analysis being incapable of representing floater performance in reality (Cunff et al. 2007; Williams \& McDougal 2013). Thus, the need for the application of Dynamic Amplification Factor (DAF), which simplifies structural dynamic analyses of linear nature. Its applications include the DAF for steel catenary risers (Quéau et al. 2011; Quéau et al. 2015), cranes, moving vehicles, buildings, trains and bridges. Another challenge is the need for proper coupling analysis on integral CALM buoy hose systems. Hose manufacturers tend to assume zero effect of wave loads when numerically assessing the strength of submarine hoses. At greater water depths, zero effect is usually used because the acceleration of water is typically negligible and the Froude-Krylov forces are estimated and can be omitted (Petrone et al. 2015). In recent times, there have been some failures in submarine hose systems from wave loads which are not predicted during the design stage (Wall et al. 2001; ABCNews 2005; MSF 2013; Oil\&GasUK 2014). The increase in the demand for hoses with longer service life from industry becomes another challenge. In addition, the assessment of the strength of submarine hoses relative to hydrodynamic loads is also challenging. Computationally, existing literature indicates that dynamic analyses on CALM with coupling of floater motion and hose hydrodynamic loads are sometime too expensive and may experience convergence issues. 


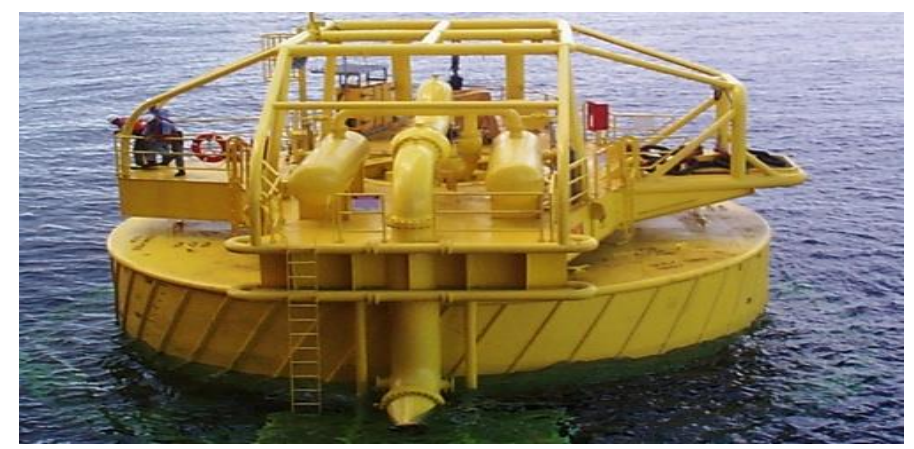

Figure 2 Offshore Buoy of Shell Malampaya Gas project (SOFEC 2017)

In this study, a coupled analysis on CALM buoy integrated hoses is carried out to study the structural performance resulting from both hydrodynamic loads and buoy motion. Parametric studies and dynamic amplification factors (DAF) are used to investigate the strength of submarine hoses. Three sea states are adopted representing West Africa Sea, North Sea and Gulf of Mexico (GoM). Hydrodynamic simulations using ANSYS AQWA are conducted to determine Response Amplitude Operators (RAO) for the CALM buoy. These RAOs obtained are then inputted into the Orcaflex models. The models are validated against analytical method. Using the verified FE models, parametric studies on possible factors that may affect the behaviour of the hoses are conducted, aiming at better understanding of the structural performance of the CALM system, and informing designers of necessary recommendations. The coupled analysis also provides a more accurate numerical model in the design of CALM buoy submarine hose string systems. Following the above investigations, a guidance dynamic amplitude factor of 2.0 considering hydrodynamic loads on hoses, $D A F_{\text {hose }}$, is recommended, which may be incorporated in the design process of such systems.

\section{Numerical Modeling}

Coupled analyses are carried out through two steps. Hydrodynamic models are firstly developed by ANSYS AQWA to determine response amplitude operators (RAO). The obtained RAOs matrix are incorporated in Orcaflex models to perform dynamic analysis.

\subsection{Hydrodynamic Model}

The hydrodynamic panel of the buoy model in ocean view is presented in Figure 3. The model is established by using ANSYS AQWA 18.2 (ANSYS 2017a; 2017b), where diffraction/radiation method is adopted to solve the 3-dimensional problem of the buoys. The buoys are designed to be operated in shallow water depth of up to $29.0 \mathrm{~m}$. For the study, the sea area employed for the fully developed flow is $50 \times 50 \mathrm{~m}^{2}$. The view of the ocean, the buoys and the sea bed are in the rectangular coordinate system denoted by XYZ. The environmental conditions used for the study is carried out according to DNVGL-RP-C205 (2017). The determined results are loaded into the Orcaflex 10.2b program (Orcina 
2014) and the results are compared to evaluate the effect of the hydrodynamic loads on the buoy and the hoses accordingly. Panel method is used in the diffraction analysis. The skirt of the buoy in the diffraction analysis is modelled as solid with smaller diameter to achieve a full representation of its effective area, as in Table 1. For the diffraction analysis, a free floating buoy is considered.

The buoy is rigid, and the forces from the diffraction analysis are used to solve the six degrees of freedom in Equation (1). A mesh convergence study is conducted based on the diffraction analysis of the buoy model. For the buoy, the maximum element size of $0.25 \mathrm{~m}$ is selected with a tolerance value of $0.01 \mathrm{~m}$. The element size was varied for a range between 0.25 and 1.25 to ensure that effective mesh density and tolerance are applied. While the mesh for the ocean environment is controlled by the ANSYS AQWA. It utilizes surface only meshing algorithm for the parts that contains only surfaces and combined meshing algorithm for the part that includes lines (ANSYS 2017c). The design mesh, time steps and the sub-spaces in the ocean environment are optimized by the software. The buoy panel model is discretized using Boundary Element Method. At the cut-water plane, source potentials are considered for the meshes in contact with the buoy using BEM (Newman \& Lee 2002; Decheng et al. 1996; Ye 1988). The convergence study helps to investigate the tension and bending behaviour of the buoy system based on the surge motion. This method of convergence study is considered because ANSYS AQWA obtains the RAO values by utilizing the potential damping, added mass and restoring force coefficients (ANSYS 2017a; Bense 2011). The effect of the maximum surge RAO acting at $0^{\circ}$ incidences were obtained, as presented in Table 2. The results indicate no significant change in the RAO value for the surge motion under the same range of wave frequencies and $0^{\circ}$ flow angle. For the meshing, it is noteworthy that there was no particular refinement on the skirt or hull of the buoy. To ensure uniformity, the meshes along the edges were the same on both the skirt and hull of the buoy. To further support the convergence study, maximum deviation on the surge RAOs is conducted. Based on the maximum deviation on $0.25 \mathrm{~m}$ mesh size, the deviations are very small $(<<5 \%)$. This study considers the tolerated deviation in the surge RAOs of the CALM buoy, which is acceptable and saves computation time.

With specific attention to the degrees of freedom in the translational direction, we can represent the general equation of motion of the body in horizontal plane as Equation (1), where $\left\{\mathbf{F}_{\mathbf{h}}\right\}$ is the hydrodynamic exciting force vector of the system, $[\mathbf{M}]$ is the mass matrix, $[\mathbf{C}]$ is the damping matrix, $[\mathbf{K}]$ is the stiffness matrix, $\{\boldsymbol{x}\}$ is the motion vector, $\{\dot{\boldsymbol{x}}\}$ is the velocity vector and $\{\ddot{\boldsymbol{x}}\}$ is the acceleration vector. The details of the matrices and vectors are in the appendix.

$$
\left\{F_{h}\right\}=[M]\{\ddot{\boldsymbol{x}}\}+[\boldsymbol{C}]\{\dot{\boldsymbol{x}}\}+[\boldsymbol{K}]\{\boldsymbol{x}\}
$$




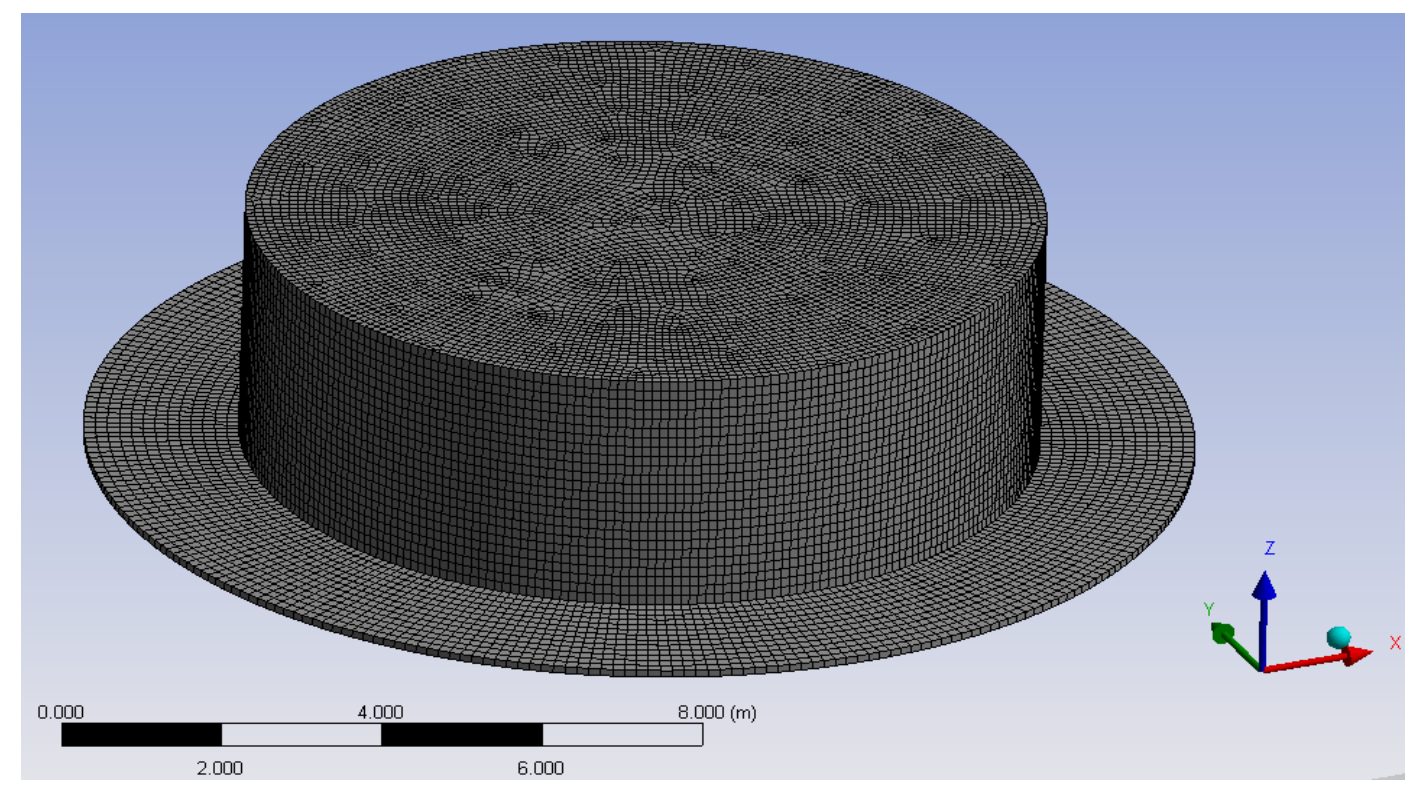

Figure 3 Hydrodynamic Panel of the Buoy (ANSYS AQWA 18.2)

Table 1 Submarine Hose Arrangement with section details

\begin{tabular}{|c|c|c|c|c|c|c|c|c|c|c|}
\hline $\begin{array}{c}\text { Hose } \\
\text { Section }\end{array}$ & Segments & Description & $\begin{array}{c}\text { Unit } \\
\text { Weight } \\
(\mathrm{kg} / \mathrm{m})\end{array}$ & $\begin{array}{c}\text { Outer } \\
\text { Diameter } \\
(\mathbf{m})\end{array}$ & $\begin{array}{c}\text { Inner } \\
\text { Diameter } \\
(\mathbf{m})\end{array}$ & $\begin{array}{c}\text { Segment } \\
\text { Length }(\mathrm{m})\end{array}$ & $\begin{array}{c}\text { Segment } \\
\text { Length } \\
(\mathrm{m})\end{array}$ & $\begin{array}{c}\text { Number } \\
\text { of } \\
\text { Segments }\end{array}$ & $\begin{array}{l}\text { Volume } \\
\left(\mathrm{kg} / \mathrm{m}^{3}\right)\end{array}$ & $\begin{array}{c}\text { Segment } \\
\text { Weight } \\
(\mathrm{kg})\end{array}$ \\
\hline \multirow{5}{*}{$\begin{array}{c}\text { Section } \\
1\end{array}$} & 1 & Fitting & 495 & 0.650 & 0.489 & 0.995 & 1.0 & 1 & 0.330 & 492.5 \\
\hline & 2 & $\begin{array}{c}\text { Reinforced } \\
\text { Hose End }\end{array}$ & 239 & 0.650 & 0.489 & 3.019 & 0.2 & 15 & 1.002 & 721.5 \\
\hline & 3 & Hose Body & 180 & 0.650 & 0.489 & 3.236 & 0.2 & 16 & 1.074 & 582.5 \\
\hline & 4 & Hose End & 200 & 0.675 & 0.489 & 0.895 & 0.5 & 2 & 0.320 & 179.0 \\
\hline & 5 & Fitting & 495 & 0.650 & 0.489 & 0.995 & 1.0 & 1 & 0.330 & 492.5 \\
\hline \multirow{5}{*}{$\begin{array}{c}\text { Section } \\
2\end{array}$} & 6 & Fitting & 495 & 0.650 & 0.489 & 0.995 & 1.0 & 1 & 0.330 & 492.5 \\
\hline & 7 & Hose End & 200 & 0.675 & 0.489 & 0.895 & 0.5 & 2 & 0.320 & 179.0 \\
\hline & 8 & Hose Body & 180 & 0.650 & 0.489 & 3.840 & 0.2 & 19 & 1.274 & 691.2 \\
\hline & 9 & Hose End & 200 & 0.675 & 0.489 & 0.895 & 0.5 & 2 & 0.320 & 179.0 \\
\hline & 10 & Fitting & 495 & 0.650 & 0.489 & 0.995 & 1.0 & 1 & 0.330 & 492.5 \\
\hline \multirow{5}{*}{$\begin{array}{c}\text { Section } \\
3\end{array}$} & 11 & Fitting & 495 & 0.650 & 0.489 & 0.995 & 1.0 & 1 & 0.330 & 492.5 \\
\hline & 12 & Hose End & 200 & 0.675 & 0.489 & 0.895 & 0.5 & 2 & 0.320 & 179.0 \\
\hline & 13 & Hose Body & 180 & 0.650 & 0.489 & 3.236 & 0.2 & 16 & 1.073 & 582.5 \\
\hline & 14 & $\begin{array}{l}\text { Reinforced } \\
\text { Hose End }\end{array}$ & 240 & 0.670 & 0.489 & 3.019 & 0.2 & 15 & 1.064 & 724.6 \\
\hline & 15 & Fitting & 495 & 0.650 & 0.489 & 0.995 & 1.0 & 1 & 0.330 & 492.5 \\
\hline
\end{tabular}

Table 2 Grid independence for diffraction analysis (Surge study)

\begin{tabular}{|l|l|l|l|c|}
\hline Element Size (m) & No. of Elements & No. of Nodes & Max. RAO (m/m) & Max. RAO Deviation on 0.25m \\
\hline 0.25 & 20156 & 20303 & 1.18664 & $0.0000 \%$ \\
\hline 0.35 & 10623 & 10728 & 1.18650 & $0.0099 \%$ \\
\hline 0.5 & 5489 & 5564 & 1.18627 & $0.0187 \%$ \\
\hline 1.0 & 1593 & 1632 & 1.18540 & $0.0556 \%$ \\
\hline 1.25 & 1113 & 1144 & 1.18470 & $0.0827 \%$ \\
\hline
\end{tabular}

\subsubsection{Hose}

The submarine hoses are in Chinese-lantern configuration, as illustrated in Figure 1. Two submarine hose strings of $25.90 \mathrm{~m}$ lengthwise, are connected to the buoy at the top and the Pipeline End 
Manifolds (PLEMs) at the bottom. The outer and inner diameters of the hoses are $0.650 \mathrm{~m}$ and 0.490 $\mathrm{m}$, respectively. Their details are given in Tables 1 and 3. Examples of submarine hoses are shown in Figure 4. The fluid contents inside, the self-weight, the buoyancy, the weight of the floats and the internal pressure are considered. The hose is fixed at both ends with no initial bending being considered. The fluid (oil) inside the hose has a density of $821 \mathrm{~kg} / \mathrm{m}^{3}$. Fully filled conditions are assumed. Uniform contents method is used to model the fluid contents. The inner pressure of the fluid inside the hose is 0 $\mathrm{kPa}$. In Orcaflex, it is modelled relative to atmospheric pressure at reference $\mathrm{Z}$ level. The submarine hose type designed was for $1,900 \mathrm{KN} / \mathrm{m}^{2}$ (19 bar) pressure application.

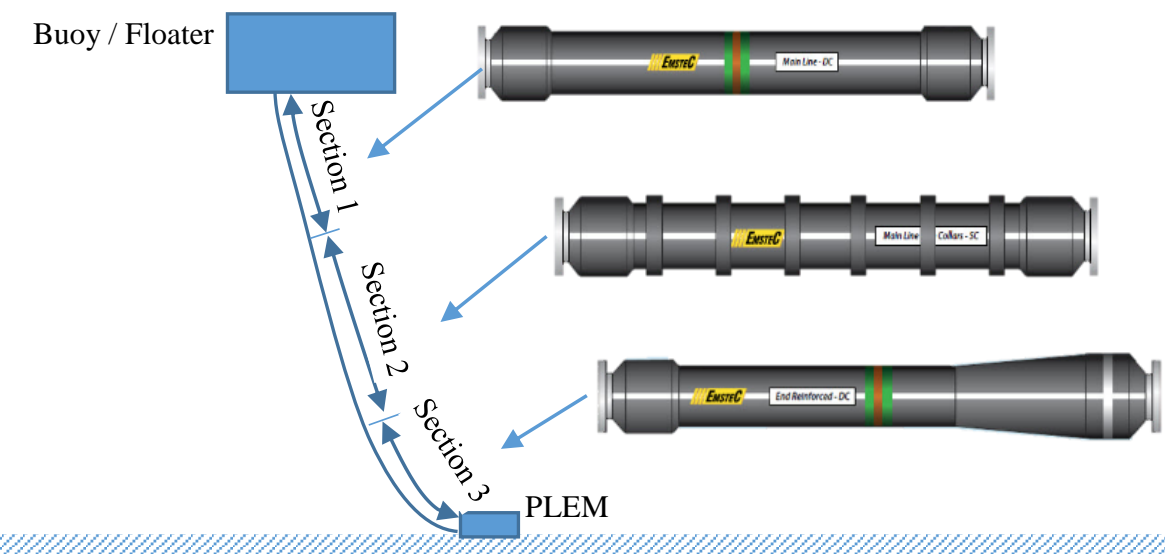

Figure 4 An illustration showing examples of submarine hoses (courtesy of EMSTEC, 2016)

Table 3 Submarine hose parameters

\begin{tabular}{|l|l|l|l|}
\hline Parameters & \multicolumn{3}{|c|}{ Value } \\
\hline Section & Section 1 & Section 2 & Section 3 \\
\hline \multirow{2}{*}{ Description } & $\begin{array}{l}\text { First-off Buoy } \\
\text { with Float collars }\end{array}$ & $\begin{array}{l}\text { Mainline without } \\
\text { Float collars }\end{array}$ & $\begin{array}{l}\text { First-off PLEM with } \\
\text { Float collars }\end{array}$ \\
\hline \multirow{3}{*}{ Arrangement of the } & R1 (fitting) & R2 (fitting) & R3 (fitting) \\
\cline { 2 - 4 } & R1 (reinforce end) & R2 (end) & R3 (end) \\
\cline { 2 - 4 } & R1 (body) & R2 (body) & R3 (body) \\
\cline { 2 - 4 } & & R2 (end) & R3 (reinforce end) \\
\cline { 2 - 4 } & R1 (fitting) & R2 (fitting) & R3 (fitting) \\
\hline Length $(\mathrm{m})$ & 8.39 & 9.02 & 8.49 \\
\hline Mass property $(\mathrm{kg} / \mathrm{m})$ & 239 & 495 & 239 \\
\hline Hose Bore $(\mathrm{m})$ & 0.490 & 0.490 & 0.490 \\
\hline
\end{tabular}

\subsubsection{Buoy}

The buoy parameters used in the design analysis are given in Table 4 .

Table 4 Buoy Parameters

\begin{tabular}{|l|c|}
\hline Parameters & Value \\
\hline Main body diameter $(\mathrm{m})$ & 10.0 \\
\hline Skirt diameter $(\mathrm{m})$ & 13.870 \\
\hline Height $(\mathrm{m})$ & 4.4 \\
\hline Draft size $(\mathrm{m})$ & 2.4 \\
\hline Water Depth $(\mathrm{m})$ & 23.0 \\
\hline Buoy Mass $(\mathrm{kg})$ & 198,762 \\
\hline
\end{tabular}




\subsubsection{Mooring Line}

A total of six mooring lines located along the circumferential direction are modelled. The mooring lines are 60 degrees apart and have the same stiffness. Each of the mooring lines are made of two sections of steel chains in the model. Both ends of the six mooring lines are anchored to the buoy and the sea bed as catenary moorings. Details of the mooring lines are presented in Figure 5 and Table 5.

Table 5 Mooring Lines Parameters

\begin{tabular}{|l|l|}
\hline Parameters & Value \\
\hline Ratio of Section Lengths & $50: 175$ \\
\hline Seabed Friction Coefficient & 0.5 \\
\hline Nominal Diameter $(\mathrm{m})$ & 0.20 \\
\hline Contact Diameter $(\mathrm{m})$ & 0.39 \\
\hline Mass per unit length $(\mathrm{kN} / \mathrm{m})$ & 0.26 \\
\hline EA $(\mathrm{kN})$ & $1,178,000$ \\
\hline Poisson Ratio & 0.5 \\
\hline Mass coefficient, $\mathrm{C}_{\mathrm{m}}$ & 1.0 \\
\hline Drag coefficient, $\mathrm{C}_{\mathrm{d}}$ & 1.2 \\
\hline
\end{tabular}

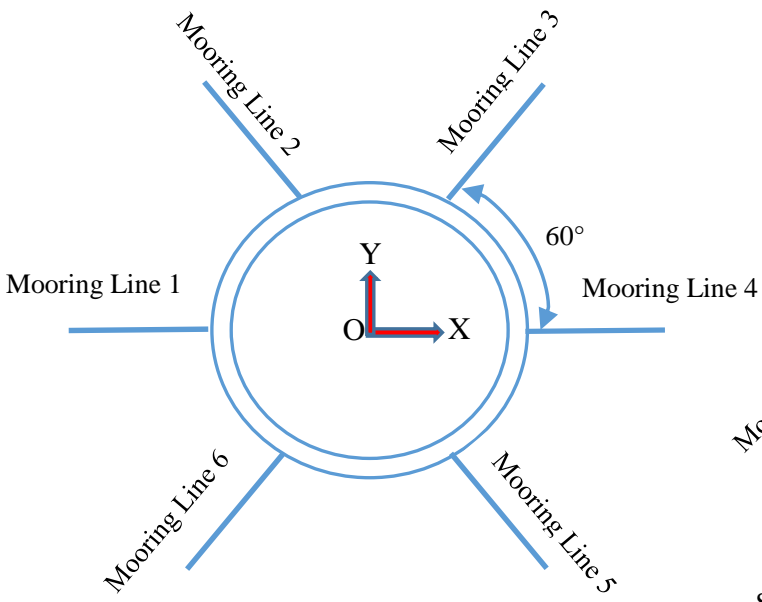

(a) Buoy Top View

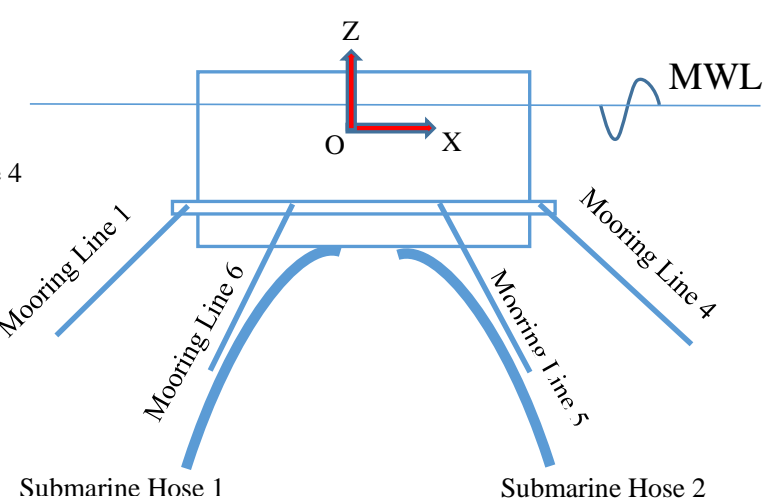

(b) Buoy Plan View

Figure 5 Local Coordinate System for Buoy and Mooring Lines in (a) buoy top view (b) buoy plan view

\subsubsection{Element Description}

Orcaflex uses lumped mass model for mooring lines and submarine hoses. This considers the line as massless with distributed concentrated mass. Figure 6 (a) shows the line segments and Fig.6 (b) shows the lumped sum model as considered in Orcaflex. In principle, the line element support flexibility of the line to have axial displacement, torsion, tension and bending. The total number of segments used in modelling the mooring lines and submarine hose lines in Orcaflex are 85 and 95 segments, respectively. A full representation of the finite element model for the buoy system in Orcaflex is shown in Figures 7-8. 


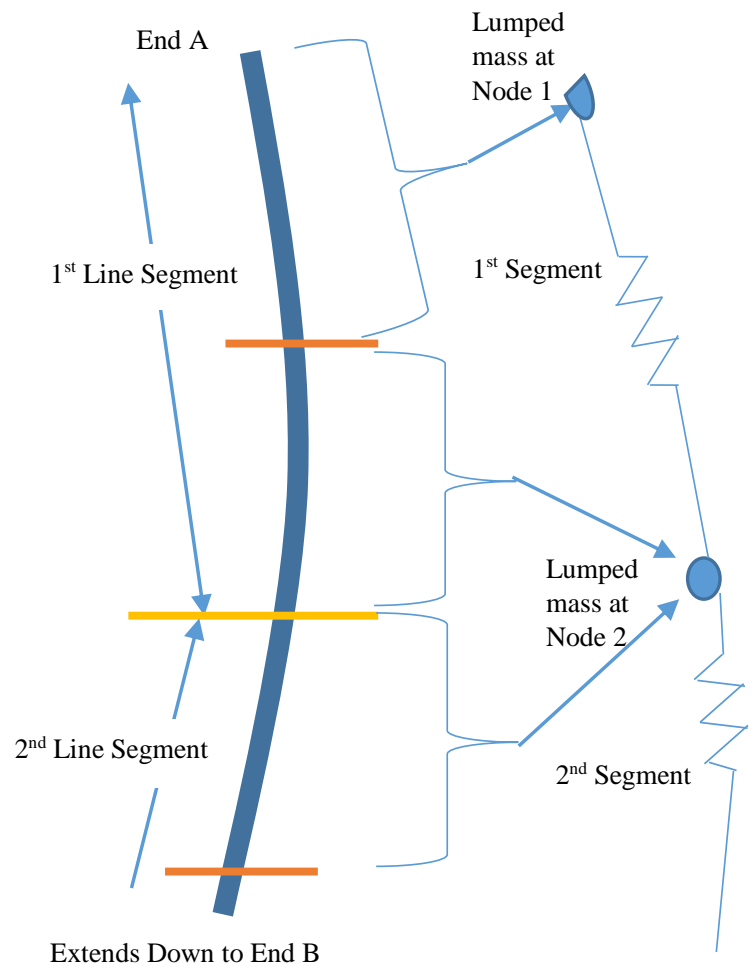

$\begin{array}{ll}\text { (a) The Main Line } & \text { (b) The Discretized Model }\end{array}$

Figure 6 Orcaflex Line Model showing (a) the main line, (b) the discretized model (courtesy of Orcina, 2014)

\subsubsection{Float (Buoyancy Attachment on Hose)}

The design for the buoyancy of the hose was designed with a float integrated as parts of the hose string. The main line of the submarine hose used in the design was without float collars, so four standard floats were attached to each of the submarine hoses. The float materials are designed as presented in Table 6 , according to the specifications in Yokohama (2016) and OCIMF (2009).

Table 6 Float Parameters

\begin{tabular}{|l|l|}
\hline Parameters & Value \\
\hline Type of Float & Standard bolted-type float \\
\hline Design Depth $(\mathrm{m})$ & 40 \\
\hline Weight in Air $(\mathrm{kg})$ & 102 \\
\hline Net Buoyancy $(\mathrm{kg})$ & 280 \\
\hline Outer Diameter $(\mathrm{m})$ & 1.23 \\
\hline Inner Diameter $(\mathrm{m})$ & 0.799 \\
\hline Float Depth $(\mathrm{m})$ & 0.6 \\
\hline Shell Material & Polyethylene \\
\hline Filling Material & Polyurethane foam \\
\hline Metal Part Material & Stainless Steel \\
\hline
\end{tabular}

\subsubsection{Seabed}

The seabed is modelled as flat surface as shown in Figure 7. The foundation of the seabed model is a non-permeable surface modelled in 3D in Orcaflex using the linear seabed theory (Orcina 2014). The parameters of the seabed are presented in Table 7. 


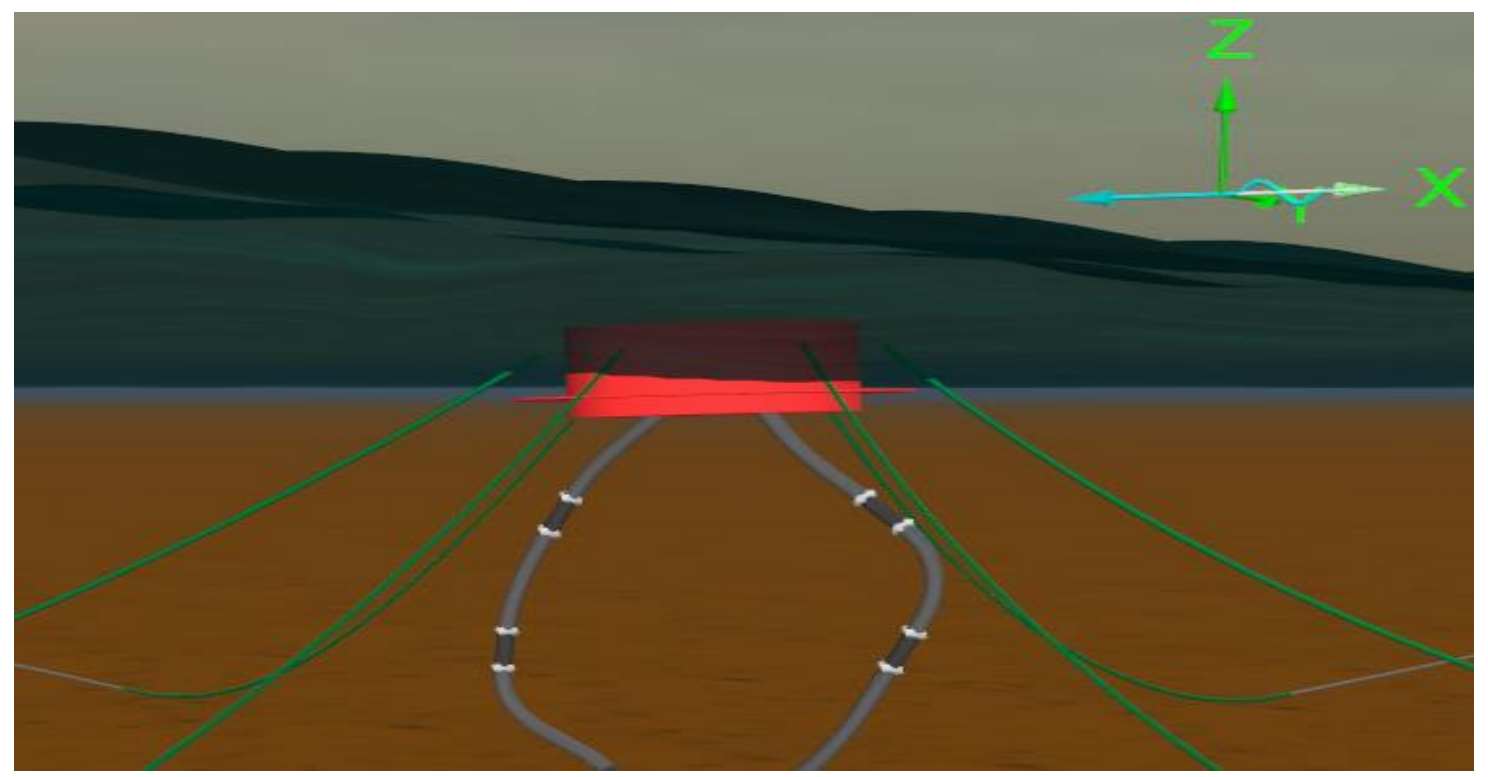

Figure 7 CALM Buoy model of submarine hoses and mooring lines in Orcaflex

Table 7 Seabed and Ocean Parameters

\begin{tabular}{|l|l|}
\hline Parameter & Value \\
\hline Water Density $\left(\mathrm{kgm}^{-3}\right)$ & 1,025 \\
\hline Ocean Kinematic Viscosity $\left(\mathrm{m}^{2} \mathrm{~s}^{-1}\right)$ & $1.35 \times 10^{-6}$ \\
\hline Wave Amplitude $(\mathrm{m})$ & 0.145 \\
\hline Seabed Stiffness $\left(\mathrm{kNm}^{-1} \mathrm{~m}^{2}\right)$ & 100 \\
\hline Seabed Critical Damping $(\%)$ & 0 \\
\hline Ocean Temperature $\left({ }^{\circ} \mathrm{C}\right)$ & 10 \\
\hline Sea Surface Height, Z $(\mathrm{m})$ & 0 \\
\hline Water Depth $(\mathrm{m})$ & 23.0 \\
\hline Seabed Slope $\left({ }^{\circ}\right)$ & 0 \\
\hline Seabed Type & Flat Seabed \\
\hline
\end{tabular}

\subsection{Dynamic model}

The Finite Element (FE) model presented in Figure 8 shows the submarine hoses, CALM buoy, mooring lines, seabed and boundary conditions. The CALM buoy is floating on an ocean acted upon by waves, currents and other hydrodynamic forces. The design of the hoses is carried out using the simple beam theory (Ye 2016), and then simulated in Orcaflex using the line theory. The design represents an offloading and loading system for a CALM buoy in Orcaflex version 10.2b, with the attached submarine hoses, floats and catenary mooring lines. The conditions are considered for irregular waves with the parameters for the ocean given in Table 4 . The velocity used in the damping calculation is the buoy velocity relative to the earth. The RAO matrix calculated through the hydrodynamic 
simulations using ANSYS AQWA are input in Orcaflex-based dynamic models, for the 21 case studies where hydrodynamic loads are included.

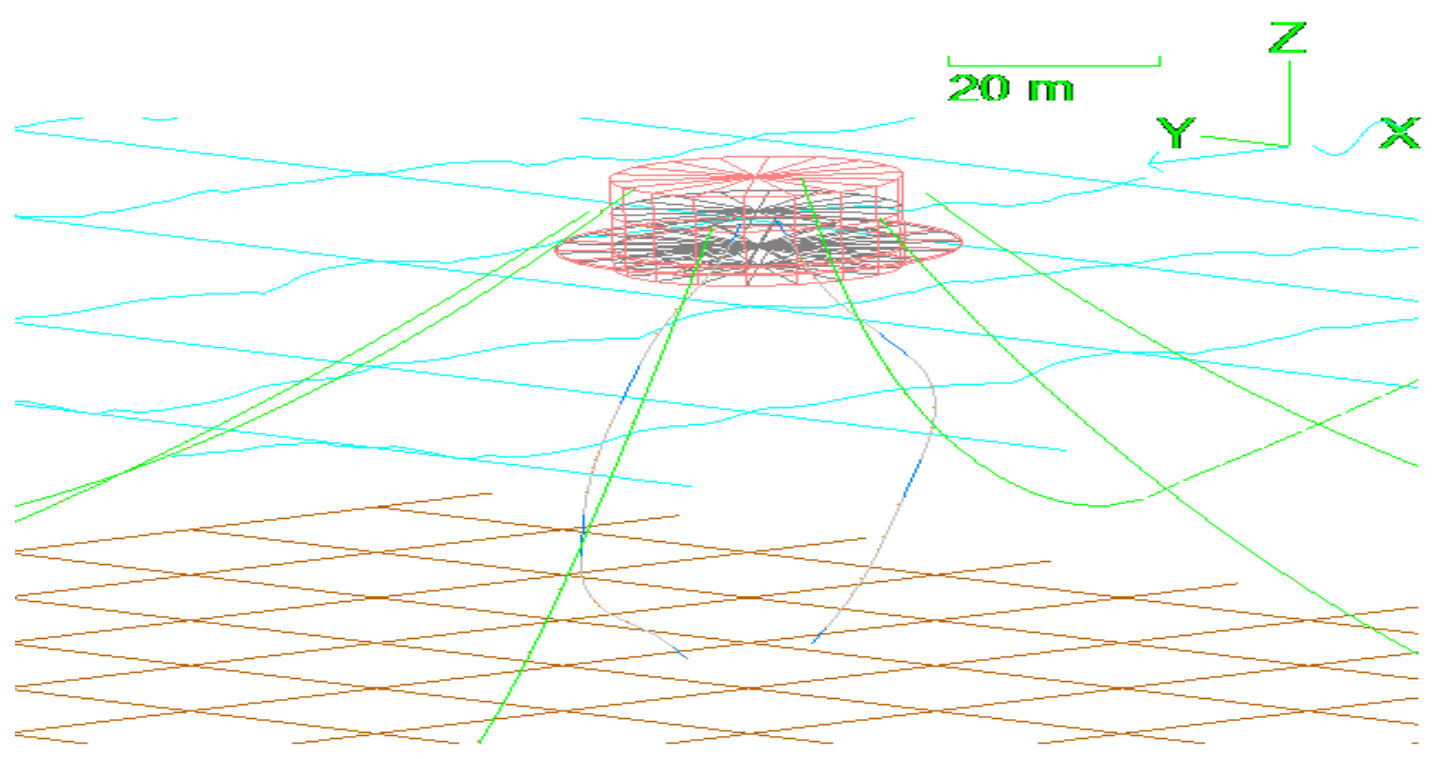

Figure 8 CALM Buoy system finite element model in Orcaflex

The calculation method for the statics of the mooring lines is the catenary method (Irvine 1981). This is presented in Equation (2), where $x$ is the section length of the mooring line, $H$ is a constant that represents the horizontal tension component, and $w$ is the weight per unit length.

$$
y=\frac{H}{w}\left[\cosh \left(w \frac{x}{H}\right)-1\right]
$$

The Finite Element Model for both the submarine hose and the mooring lines are considered to have effects from both bending and axial loads, similar to the offshore hose model by O'Donoghue \& Halliwell (1990). Each mooring line contributes to the load effect of the system, with respect to its relative position, velocity and acceleration.

\subsubsection{Waves}

The JONSWAP (Joint North Sea Wave Project) Spectrum, which has been widely used to simulate wave conditions worldwide (Duggal \& Ryu 2005; Kang et al. 2014; Ryu et al. 2006; O'Sullivan 2002; O'Sullivan 2003), is used in this study for the environmental simulation module integrated in Orcaflex. The JONSWAP spectrum is modified originally from the Pierson-Moskowitz spectrum (Hasselmann et al. 1973; Chakrabarti 2001; 2005). In this study, the linear theory with respect to the spectral components is used in the simulation of the sea state. The simulations are run for irregular waves in fully developed sea conditions, for the duration of 3 hours. A JONSWAP wave spectrum with peak factor of 3.3 is used in all the sea states, as shown in Figure 9. This study employs three combinations of environmental conditions. The key parameters including significant heights $H_{\mathrm{s}}$, zero-up-crossing period $T_{\mathrm{z}}$ and peak period $T_{\mathrm{p}}$, are presented Table 8 . 
Table 8 Parameters for the Wave Parameters for 3 Cases

\begin{tabular}{|l|l|l|l|}
\hline Project & $\boldsymbol{H}_{\mathbf{S}}(\mathbf{m})$ & $\boldsymbol{T}_{\mathbf{Z}}(\mathbf{s})$ & $\boldsymbol{T}_{\mathbf{P}}(\mathbf{s})$ \\
\hline 1 & 1.87 & 4.10 & 5.27 \\
\hline 2 & 2.20 & 5.60 & 7.20 \\
\hline 3 & 4.10 & 7.00 & 9.00 \\
\hline
\end{tabular}

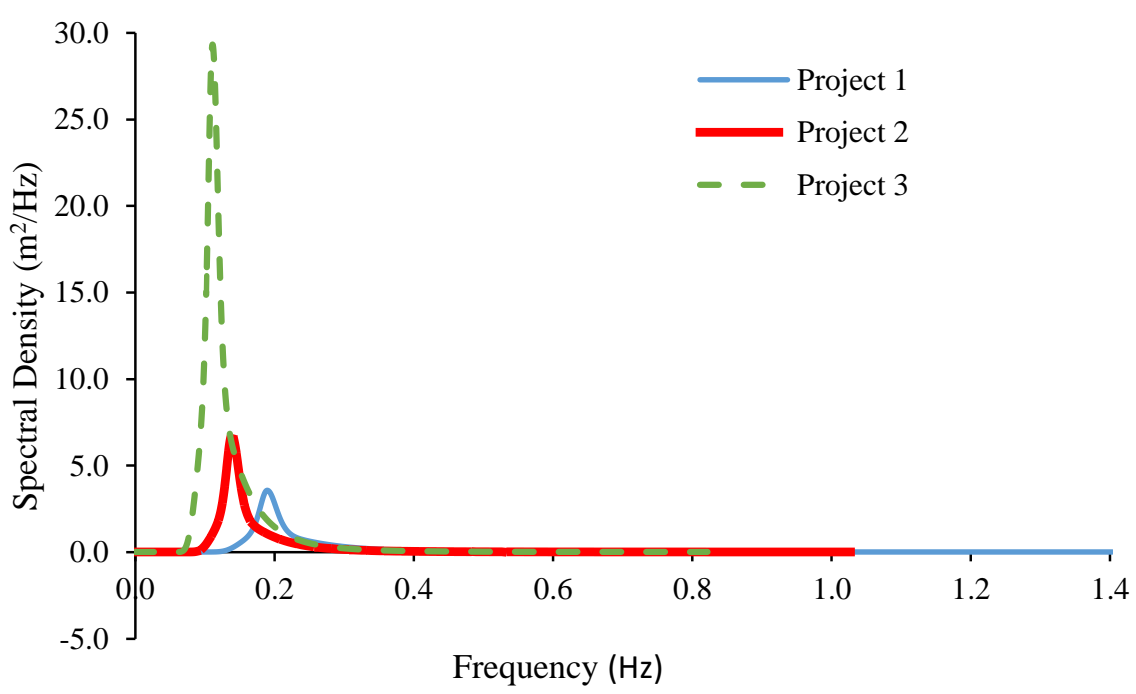

Figure 9 JONSWAP Spectrum for the 3 Environmental Cases

\subsubsection{Current and Wind}

The current parameters for this study are presented in Table 9. The speeds of current and wind are set as $0.5 \mathrm{~m} / \mathrm{s}$ and $22 \mathrm{~m} / \mathrm{s}$, respectively, and are always in the same direction. Both the current and wind loads act in the XY plane. Uniform current profile is applied on the submarine hoses at each flow angle. Wind loads on both the CALM buoy and submarine hoses are included in the model. Figures 10 and 11 depict the current and wind load coefficients for the CALM buoy systems, showing the motions of the surge, sway and yaw, respectively. This was obtained from response study on the CALM buoy using ANSYS AQWA, where the fundamental frequency (lowest frequency) used in the study is $0.06048 \mathrm{~Hz}$. 
Table 9 Current and Wind Parameters

\begin{tabular}{|l|l|}
\hline Parameter & Value \\
\hline Air Density $\left(\mathrm{kgm}^{-3}\right)$ & 0.0013 \\
\hline Air Kinematic Viscosity $\left(\mathrm{m}^{2} \mathrm{~s}^{-1}\right)$ & $15.0 \times 10^{-6}$ \\
\hline Current Method & Interpolation \\
\hline Wind Type & Constant \\
\hline Wind Speed $\left(\mathrm{ms}^{-1}\right)$ & 22.0 \\
\hline
\end{tabular}

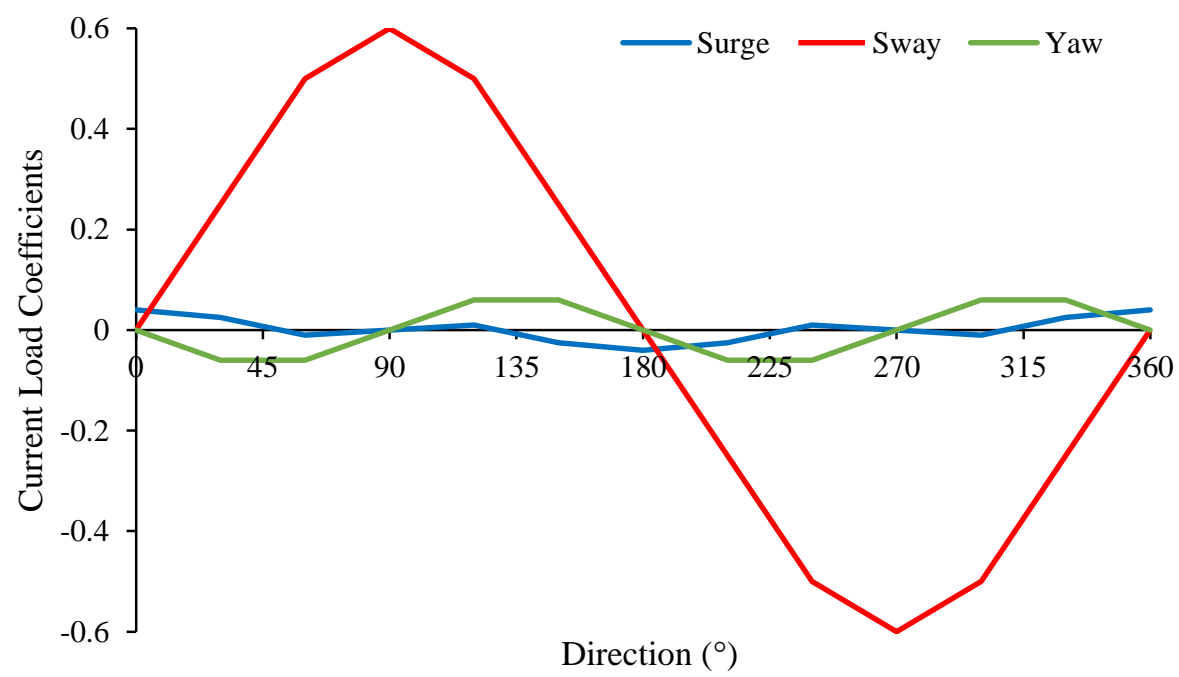

Figure 10 Current Load Coefficient for CALM buoy system

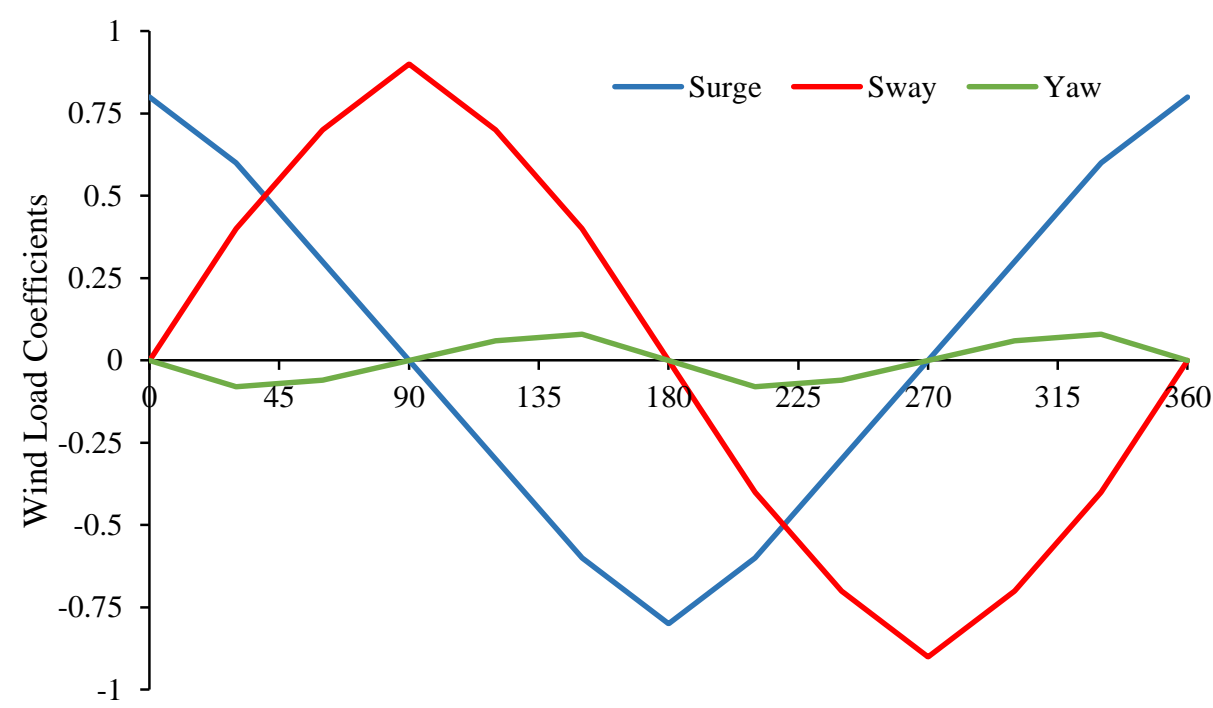

Direction $\left(^{\circ}\right)$

Figure 11 Wind Load Coefficient for CALM buoy system 


\subsubsection{Case Studies}

To clarify the influence of hose hydrodynamic loads on the structural behaviour of the hose, contrastive analysis is conducted. The cases for this study are defined as Case I (without hose hydrodynamic loads) and Case II (with hose hydrodynamic loads). Three environmental conditions, representing West Africa Sea, North Sea and Gulf of Mexico (GoM), respectively, are adopted. For each case, seven different flow angles: $0^{\circ}, 30^{\circ}, 60^{\circ}, 90^{\circ}, 120^{\circ}, 150^{\circ}$ and $180^{\circ}$ are considered as shown in Table 10. Wave and current angles are kept the same in the analysis. A total of 42 cases are subsequently studied. Each simulation is run for three hours (real time) as the time for fully developed waves.

Table 10 Definition of Case Study for the 3 Cases

\begin{tabular}{|l|l|l|}
\hline Environmental condition case & Hose hydrodynamic loads & Flow Angles $\left(^{\circ}\right)$ \\
\hline 1 & with, without & $0,30,60,90,120,150,180$ \\
\hline 2 & with, without & $0,30,60,90,120,150,180$ \\
\hline 3 & with, without & $0,30,60,90,120,150,180$ \\
\hline
\end{tabular}

\subsubsection{Hydrodynamic Loads Consideration}

The hydrodynamic loads that are considered in this study includes: displacement and load RAOs wave dependent added mass and damping, full wave drifts and full QTFs. In addition, the effect of the skirt on the buoy also affects the hydrodynamic behaviour. Another important aspect is the kinematics of the flow that induces both inertia loads and drag forces on the submarine hoses and the mooring lines attached to the CALM buoy (Berhault et al. 2004; Cunff et al. 2007).

\section{Wave-dependent Added Mass}

The damping calculation is carried out with the buoy relative to the earth. The calculation of the hydrodynamic loads without RAOs is carried out by dividing the buoy into cylinders and the values for the added mass specified for each cylinder. The RAO matrix calculated through the hydrodynamic simulations using ANSYS AQWA are input in Orcaflex-based dynamic models for the 21 case studies where wave load RAO are included. For the cases without the hydrodynamic loads, the normal added mass force coefficient is 0.5 while the axial added mass force coefficient is 1.0. However, when the hydrodynamic loads are considered with the wave load RAOs and the matrices, the calculation of the added mass is carried out by considering the entire buoy. The RAO values are obtained from diffraction/radiation analysis in frequency domain using ANSYS AQWA. Due to the fluid surface interaction, the segment of the buoy that is partially submerged is proportioned, depending on the hydrostatic stiffness and the hydrodynamic loads. The inertia of the buoy is considered in relation to the local axes and applied at the centre of the wetted volume, where added mass is equal to the product of the proportion wet and moment of area (Orcina 2014). 


\section{Wave-dependent Hydrodynamic Damping}

The study is carried out with irregular wave, and the damping is calculated using the following modified Morison Equation (Morison et al. 1950).

$$
F=\rho V \dot{u}+\rho C_{a} D A\left(V_{r}\right)+\frac{1}{2} \rho C_{d} A\left(V_{r}\right)\left|V_{r}\right|
$$

where $V$ is the volume of the body, $A$ is the area of the body, D is the diameter of the body, $C_{\mathrm{d}}$ is the drag coefficient, $C_{\mathrm{a}}$ is the added mass coefficient, $C_{\mathrm{m}}$ is the inertial force coefficient, and the $V_{r}$ is the relative velocity of fluid particles.

The buoy is divided into cylinders and the values for the added mass specified for each cylinder to calculate for the hydrodynamic loads without RAOs. The contribution of the added mass to the Morison's equation is directly proportional to the volume that has been displaced. Thus, the same added mass property is assigned for the entire buoy model. Also, $C_{\mathrm{a}}$ of the buoy and the cylinder below the skirt are 1.0 and 5.0, respectively.

\section{Drag Forces}

The drag coefficient for the buoy is set to zero at the sections above the skirt, because those regions are shielded from the fluid flow. In order to calculate the drag forces, the buoy is discretised into cylinders that are connected to create a rigid body. Negligible mass, zero inertia and zero mass moments of inertia are applied for the cylinders. The drag forces as a result of the hydrodynamic loads due to drag and inertia on both the mooring lines and the submarine hoses are calculated using a set of equations as those in (Cozijn \& Bunnik 2004).

\section{Linear Transfer Function}

The effect of the linear transfer function on the buoy is very minimal, due to the nonlinearities arising from the viscous drag. However, it has an effect on the hydrodynamic loading of the system as the higher order transfer functions generate better exciting force approximations. The values for the linear wave frequency damping coefficients are all zero, except in the roll direction that is 3.6e4 $\mathrm{kN} . \mathrm{m} / \mathrm{rad} / \mathrm{s}$. Irregular waves are used in the analysis, which also included effects of nonlinear damping. The buoy motions are observed to be sensitive to the wave heights close to the natural frequencies and thus affect the curvature of the hoses. Hence, more simulations are carried out to full wave period to produce different wave spectra for different case studies.

Table 11 Parameters for Buoy Hydrostatics

\begin{tabular}{|l|l|}
\hline Parameters & Value \\
\hline Area $\left(\mathrm{m}^{2}\right)$ & 438.49 \\
\hline Volume $\left(\mathrm{m}^{3}\right)$ & 344.98 \\
\hline Moment of Inertia, $\mathrm{I}_{\mathrm{xx}}\left(\mathrm{Kg} \cdot \mathrm{m}^{2}\right)$ & 4331379.37 \\
\hline Moment of Inertia, $\mathrm{I}_{\mathrm{yy}}\left(\mathrm{Kg} \cdot \mathrm{m}^{2}\right)$ & 4486674.11 \\
\hline Moment of Inertia, $\mathrm{I}_{\mathrm{zz}}\left(\mathrm{Kg} \cdot \mathrm{m}^{2}\right)$ & 4331379.37 \\
\hline Centre of Gravity $(\mathrm{m})$ & -2.2 \\
\hline Buoyancy Force $(\mathrm{N})$ & $1,967,500 \mathrm{~N}$ \\
\hline
\end{tabular}




\subsubsection{Analysis Methodology}

The analysis is carried out in phases, first by carrying out the hydrodynamic analysis of the CALM buoy in ANSYS AQWA. This is first done using a buoy that is free from any attachment like hoses or mooring lines. The added mass, radiation damping and RAO are then obtained. Details about RAO of offshore structures can be found in Wilson (2003) and Bishop \& Price (2005). The buoy parameters for the hydrostatics are presented in Table 11, where values are according to the local coordinate system. At free-floating equilibrium position, the buoyancy force acts at the $\mathrm{Z}$-axis position at the Centre of Gravity (CoG). The hydrostatic stiffness matrix for the buoy are loaded into Orcaflex for the dynamic analysis, as specified by ABS (2014) and DNVGL (2015). For an operation condition, the submarine hoses are attached to the CALM buoy, and six mooring lines are used to tension the CALM buoy to the seabed as presented in Figure 5. The analysis aimed at operation and survival conditions for intact mooring. For the scope of this paper, the full operation with connection of the oil tanker to the CALM buoy and the hawser lines are not considered. The load cases for the hose analysis presented in Table 12 are not fully presented in this paper. The buoy offset, the mooring arrangement, and the critical environmental heading are studied to obtain the worst case scenario for extreme conditions. The 100year extreme wind condition is considered for both wind and current.

Table 12 Load Case for Hose Analysis

\begin{tabular}{|c|c|c|c|c|}
\hline Conditions & Heading & Tanker & Mooring & Configuration \\
\hline \multirow[t]{4}{*}{ Operation } & Cross & Yes & \multirow[t]{2}{*}{ Intact } & \multirow[t]{4}{*}{ Chinese-lantern } \\
\hline & Inline & Yes & & \\
\hline & Cross & Yes & \multirow[t]{2}{*}{ Damage } & \\
\hline & Inline & Yes & & \\
\hline \multirow[t]{4}{*}{ Survival } & Cross & Yes & \multirow[t]{2}{*}{ Intact } & \multirow[t]{4}{*}{ Chinese-lantern } \\
\hline & Inline & Yes & & \\
\hline & Cross & Yes & \multirow[t]{2}{*}{ Damage } & \\
\hline & Inline & Yes & & \\
\hline \multirow[t]{4}{*}{ Extreme } & Cross & No & \multirow[t]{2}{*}{ Intact } & \multirow[t]{4}{*}{ Chinese-lantern } \\
\hline & Inline & No & & \\
\hline & Cross & No & \multirow{2}{*}{ Damage } & \\
\hline & Inline & No & & \\
\hline
\end{tabular}

\subsection{Validation}

Firstly, the Orcaflex static models are compared with the corresponding analytical catenary equations for the horizontal and vertical forces, $T_{\mathrm{h}}$ and $T_{\mathrm{v}}$, at the top end of the hose. Analytical catenary equations may provide a preliminary assessment on hose configurations during very early stage in engineering practices, provided that the dynamic response of the hose is minor or can be reflected through a well-defined dynamic amplitude factor (DAF). The expressions of $T_{\mathrm{h}}$ and $T_{\mathrm{v}}$ through analytical centenary equations (Bai \& Bai, 2005) are given in Equations (4) and (5);

$$
T_{h}=\frac{z \cdot w_{S}}{(\tan \theta)^{2}} \cdot\left(1+\sqrt{ }\left(1+(\tan \theta)^{2}\right)\right)
$$

$$
T_{v}=w_{s} \cdot s
$$


where $z$ is height above seabed, $w_{\mathrm{s}}$ is submerged weight, $\theta$ is angle to the horizontal axis and $s$ is arc length.

The results from both the finite element analysis and the analytical calculations are presented in Table 13. The analytical and finite element results for vertical tensions are $81.6 \mathrm{kN}$ and $78.5 \mathrm{kN}$ respectively. The analytical and finite element results for horizontal tensions are $109.3 \mathrm{kN}$ and 115.4 $\mathrm{kN}$ respectively. Good agreements between both approaches are observed with variations of $3.9 \%$ and $5.3 \%$, respectively, for the vertical and horizontal forces, as shown in Table 13.

Secondly, upon the verified static models, the dynamic effects provided by Orcaflex was assessed on catenary S-lay pipeline through recently accomplished sea trials (Wang et al., 2017). Thus, the Orcaflex dynamic models are expected to be capable of performing dynamic analysis on the hose in centenary configuration.

Table 13 Comparison of results for validation for hose MBR and maximum tension

\begin{tabular}{|l|l|l|}
\hline & $\begin{array}{l}\text { Vertical Tension } \\
(\mathrm{KN}), T_{\mathrm{v}}\end{array}$ & $\begin{array}{l}\text { Horizontal } \\
\text { Tension }(\mathrm{KN}), T_{\mathrm{h}}\end{array}$ \\
\hline Analytical & 81.6 & 109.3 \\
\hline Orcaflex (FE) & 78.5 & 115.4 \\
\hline Mean (Analytical/Orcaflex) & 1.039 & 0.947 \\
\hline
\end{tabular}

\section{Parametric Studies}

A series of parametric studies are conducted to study the structural behaviour of the hoses with and without hydrodynamic loads being considered. Environmental conditions of Project 1 presented in Tables 8-10 are used to investigate the effects of flow angles on the structural performance of the hoses in terms of bending moments, effective tensions and curvatures. The bending moments, effective tensions and curvatures along the arc length are recorded when the maximum hose effective tensions are attained. Hose 1 (leeside) and Hose2 (weatherside) are considered. DAF (Dynamic amplitude factor) is defined as the ratio of the dynamic response amplitude to the static response amplitude (Barltrop \& Adams 1991; Barltrop 1998), as shown in Equation (6).

$$
D A F_{\text {Hose }}=\frac{\text { Dynamic Response Amplitude }(\text { With hydrodynamic loads on Hose })}{\text { Static Response Amplitude }(\text { Without hydrodynamic loads on Hose })}
$$

The structural behaviours of the hoses with and without considering hydrodynamic loads are both analysed accordingly.

\subsection{Bending Moment}

For Project 1, the distributions of bending moments along the hose arc length for the cases with and without hydrodynamic loads are presented in Figures 12 (a-d), respectively. The bending moments at the both ends have significantly higher values than those in between since the hose has higher flexural stiffness at both the top connection and the touch down point area. For each case, a total of 7 different flow angles are considered. For the cases with hose hydrodynamic loads, the distributions of the bending

*Correspondence authors: j.ye2@lancaster.ac.uk (J.Ye); wangfacheng@tsinghua.edu.cn (F.Wang) 
moments at both ends of the hoses are significantly higher than those in between, except for the simulation with $90^{\circ}$ flow angle. This is attributed to the twisting behaviour of the hose end connecting the CALM buoy. Compared with the initial hose position, twisted hose may be threatened by fluids since the moving content may hit the internal surface of the hose at locations with significant twisting deformations. The twisting is associated with flow angle. As the hose twists, the bending moment changes along the arc length of the hose.

For the cases where hydrodynamic loads are not considered, smoother distributions of bending moments along the arc length were observed. For both cases with and without hose hydrodynamic loads, as shown in Fig. 12 (a-d), the simulations with $90^{\circ}$ flow angle generally give lowest bending moments throughout the hose arc length, while the largest bending moments are found from models with either $0^{\circ}$ or $180^{\circ}$ flow angle. This may be attributed to that the $90^{\circ}$ flow induces greater twist moment that causes rotation of the buoy. Thus more energy is dissipated through twisting than bending due to the relatively lower stiffness of the buoy against torsion than bending.

The $D A F_{\text {Hose }}$ throughout the hose arc length are determined for both Hose 1 and Hose2 and are presented in Figures 12 (e-f), respectively. A guidance value of 2.0 for bending moment $D A F_{\text {Hose }}$ is recommended accordingly and regarded in line with engineering practice. Maximum bending moments were observed at the connections due to the high viscous drag on the buoy. Thus the damping coefficient used is 1.0 which takes care of the first order wave loads on the buoy.

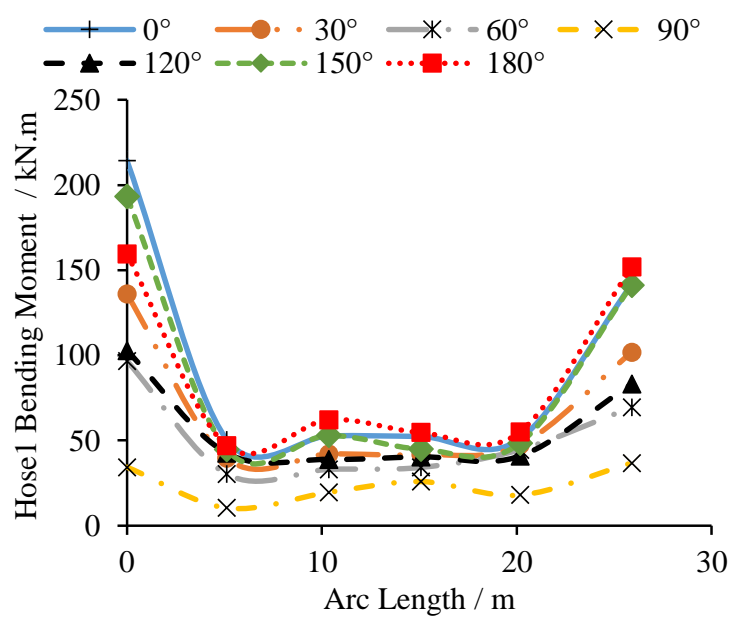

(a) Bending moment for Hose1 with hose hydrodynamic load

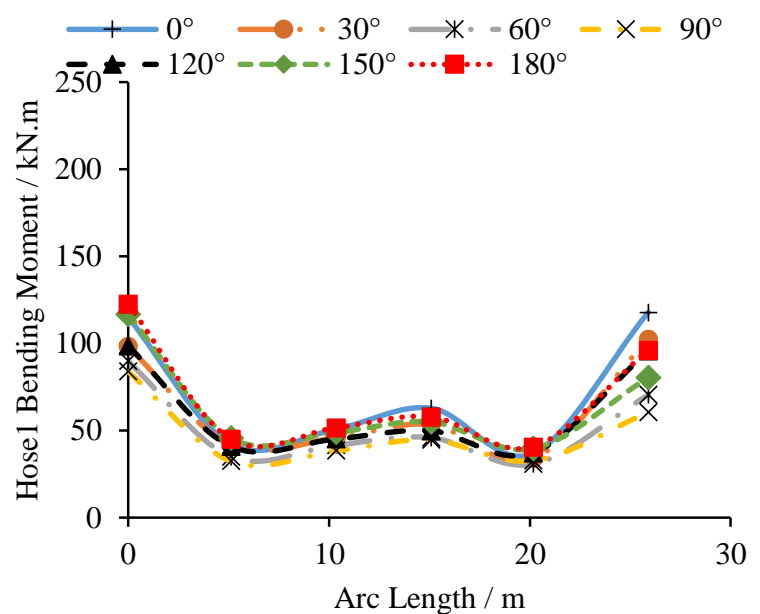

(b) Bending moment for Hose1 without hose hydrodynamic load 


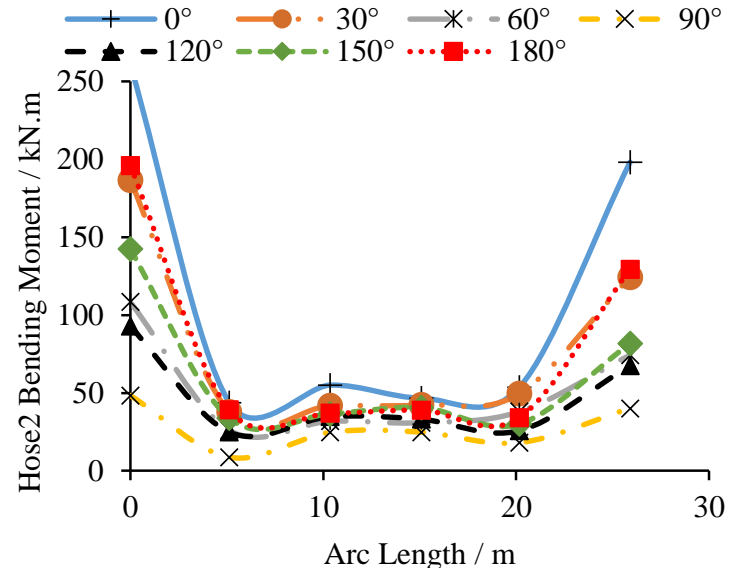

(c) Bending moment for Hose2 with hose hydrodynamic load

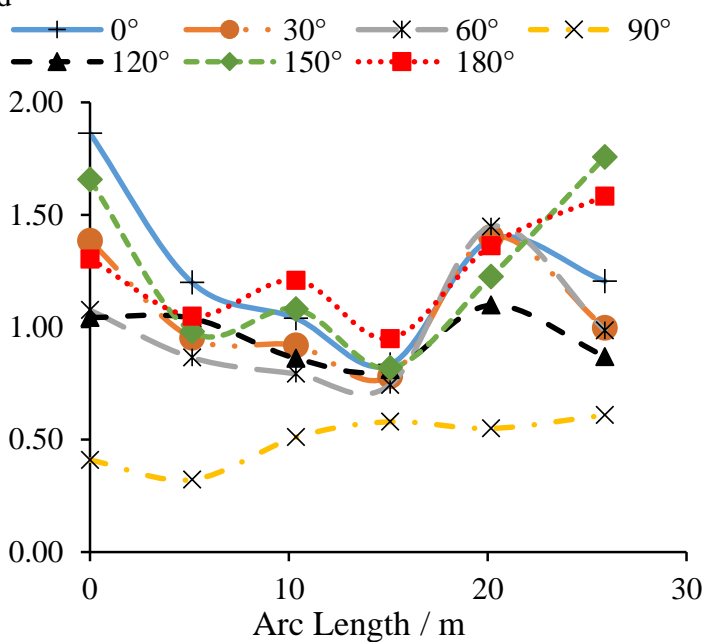

(e) Hose 1 bending moment $D A F_{\text {Hose }}$

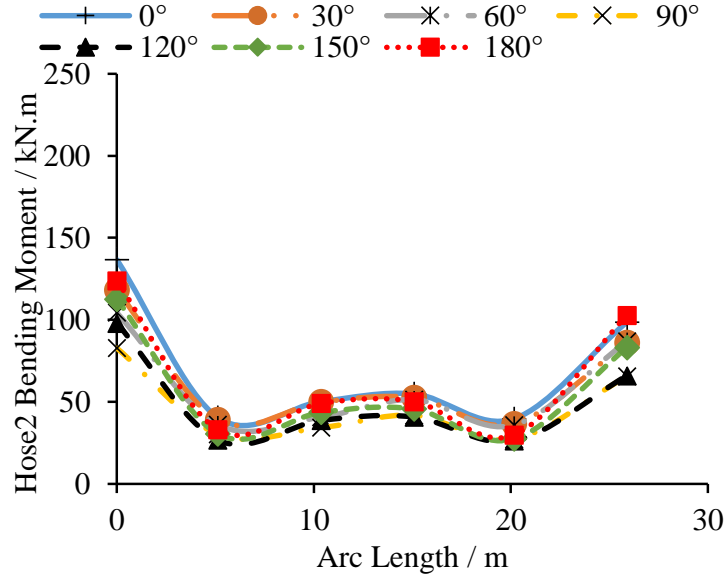

(d) Bending moment for Hose2 without hose hydrodynamic load
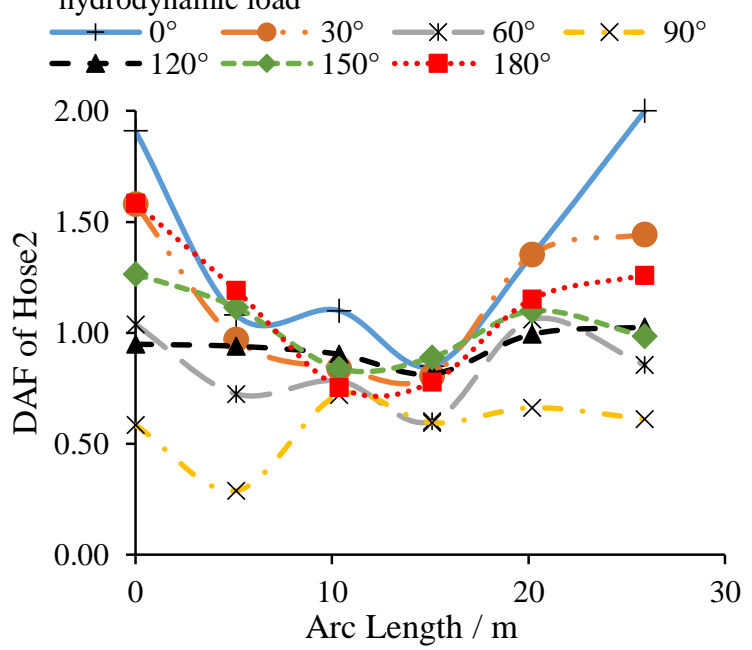

(f) Hose 2 bending moment $D A F_{\text {Hose }}$

Figure 12 Effect of RAOs on bending moments

\subsection{Effective Tension}

The distributions of the effective tension along the hose arc length for the cases with and without hydrodynamic loads are presented in Figures 13 (a-d) respectively. The distributions of the tensions along the hose arch lengths are not fluctuated in such extent as bending moments as shown in Figure 12, since tensions are not highly associated with flexural stiffness. Again, a total of 7 different flow angles are considered. Models with $0^{\circ}$ or $180^{\circ}$ flow angle generally gives larger predictions on effective tension and curvatures than those with $90^{\circ}$ flow angle. The effective tensions in the simulations with $0^{\circ}$ or $180^{\circ}$ may be increased if the hose hydromantic loads are considered. Similar level of effective tensions were observed at both ends of the hose, which are significantly higher than those along other parts of the arc length in-between. The hose at both ends have highest axial and flexural stiffness due to the restrains and that the rest parts are relatively flexible. To withstand hydrodynamic loadings, more flexible hose parts may have less bending moments accordingly. 
Figures 13 (e-f) give the distributions of effective tension $D A F_{\text {Hose }}$ along the arc length for Hose 1 and Hose 2, respectively. The same as Section 3.1, a guidance value of 2.0 for effective tension $D A F_{\text {Hose }}$ is recommended according to the analyses presented in Fig. 13 (e-f) and such values are in line with existing engineering design practice. Significant tensions are determined at the connections. This might be attributed to the higher response from wave frequency motion, induced by the wave drift and damping.
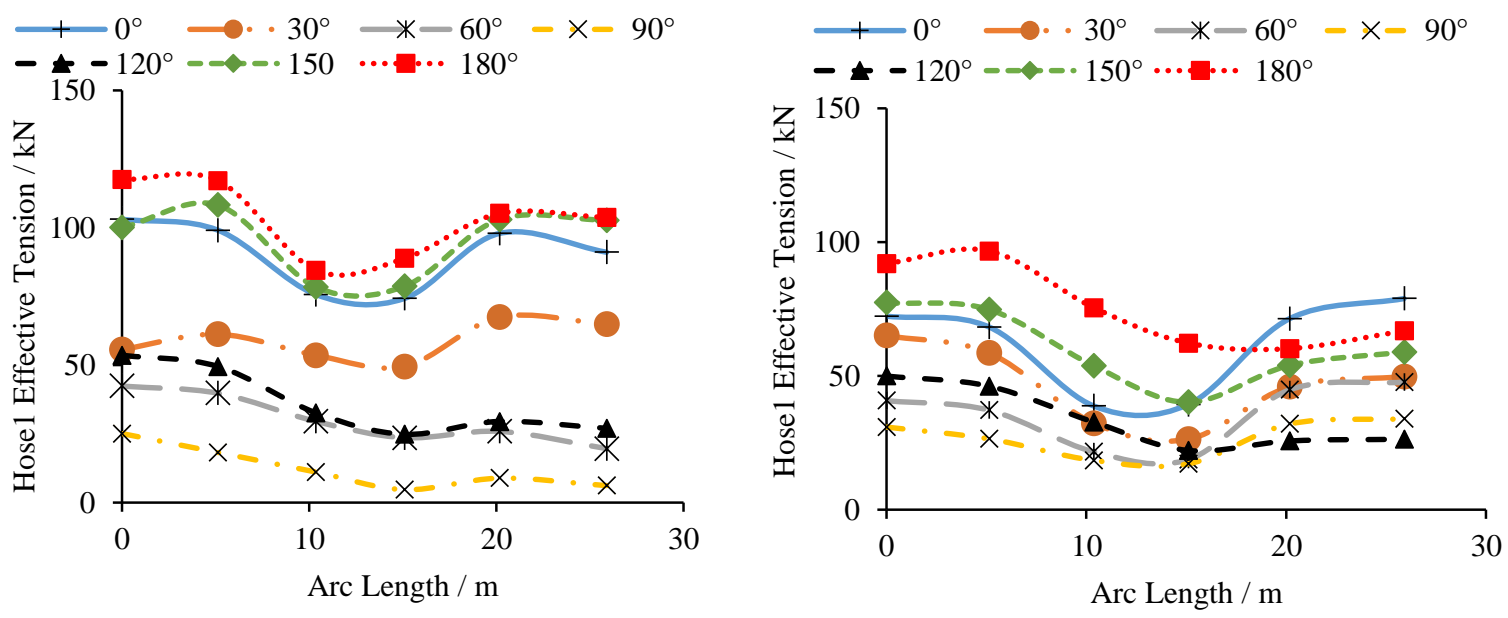

(a) Effective Tension for Hose1 with hose hydrodynamic load (b) Effective Tension for Hose1 without hose hydrodynamic

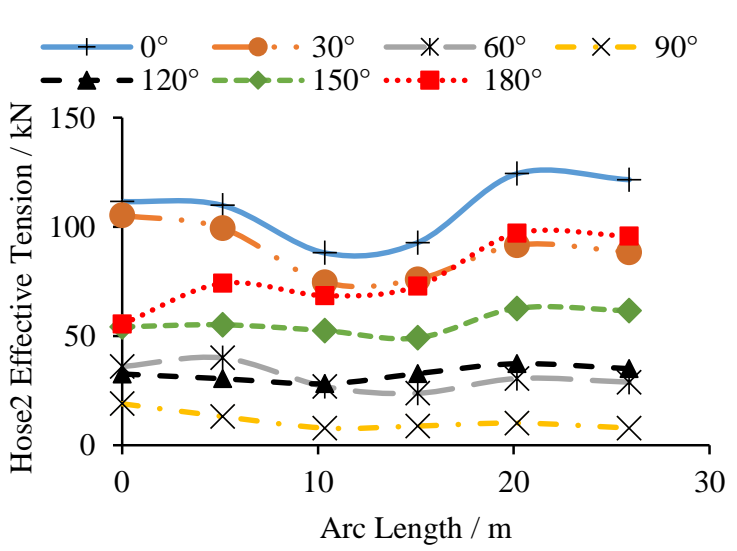
load

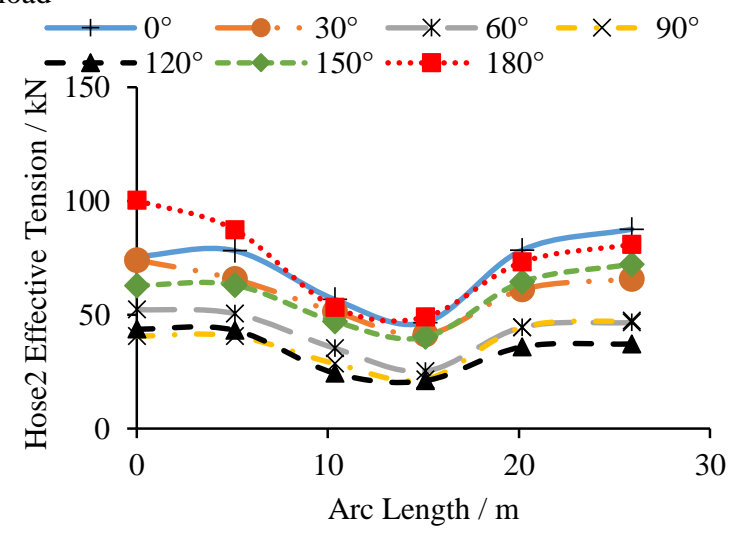

(c) Effective Tension for Hose2 with hose hydrodynamic load (d) Effective Tension for Hose2 without hose hydrodynamic load

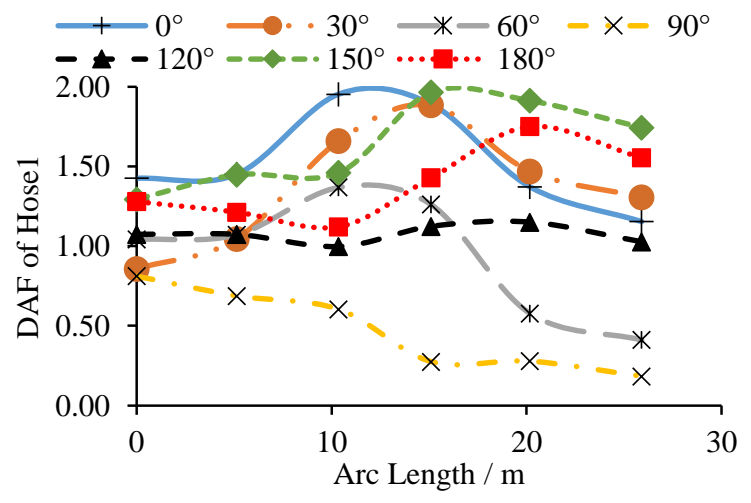

(e) Hose 1 Effective Tension $D A F_{\text {Hose }}$

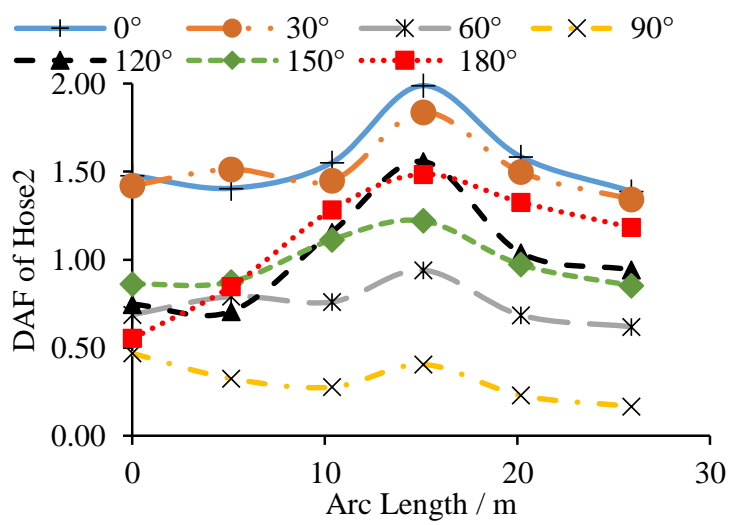

(f) Hose 2 Effective Tension $D A F_{\text {Hose }}$ 


\section{Figure 13 Effect of effective tensions}

\subsection{Curvature}

The distributions of curvature along the hose arc length for the cases with and without hydrodynamic loads are presented in Fig. 14 (a-d), respectively. MBR is a limit of the curvature, equal to an inverse of the curvature. At these sections on the arc lengths, there is some deformation in the hose. This is observed from both the deformation and the curvature in the dynamic analysis of the submarine hoses. As can be seen in Fig. 14 (a-d), the models with $90^{\circ}$ flow angle generally are generally observed with lowest curvature along the hose arc length. The values may be further reduced by considering the hose hydrodynamic loads. Hoses subjected to cross-flow $\left(0^{\circ}\right.$ or $\left.180^{\circ}\right)$ generally show larger curvatures that increase further when the hose hydrodynamic loads are considered. The comparisons of the curvature distributions between the cases with and without hydrodynamic loads are shown in Figure 14 (e-f) by the curvature $D A F_{\text {hose }}$ along the arc length. Since the hose may withstand significant bending around the locations where the floats are connected, more reinforcements are suggested at those locations. Again, the same guidance value of 2.0 for curvature $D A F_{\text {Hose }}$ is recommended accordingly.

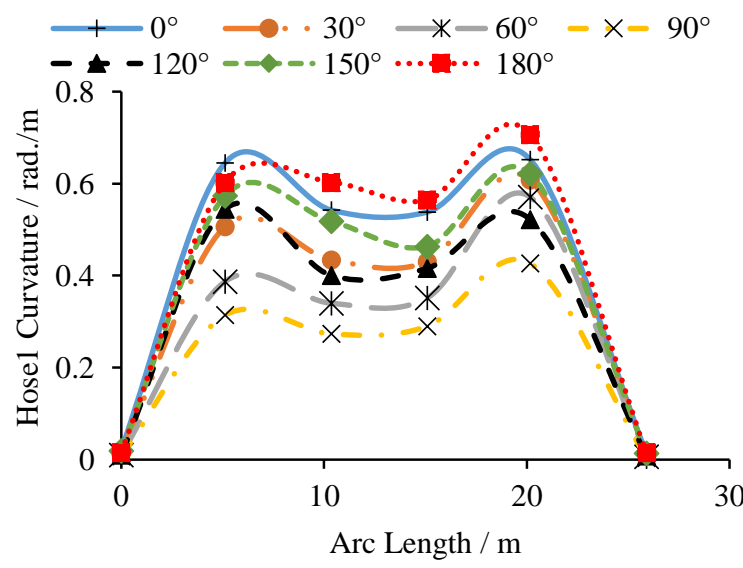

(a) Curvature for Hose1 with hose hydrodynamic load

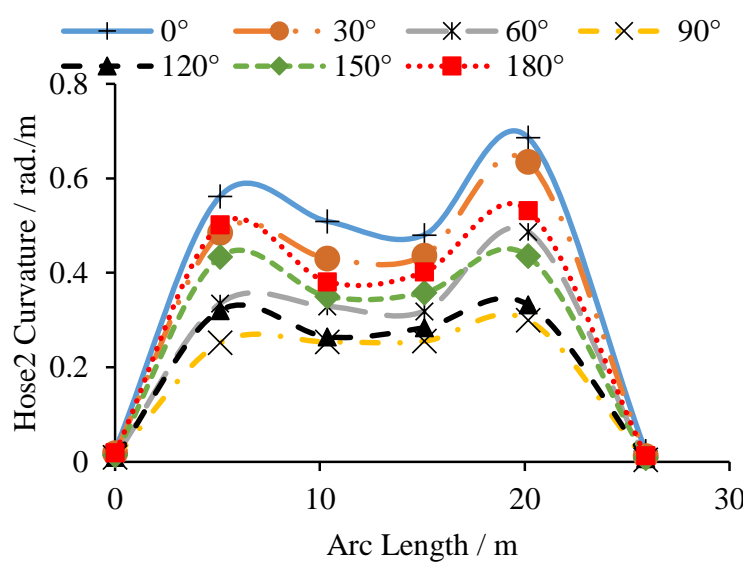

(c) Curvature for Hose2 with hose hydrodynamic load

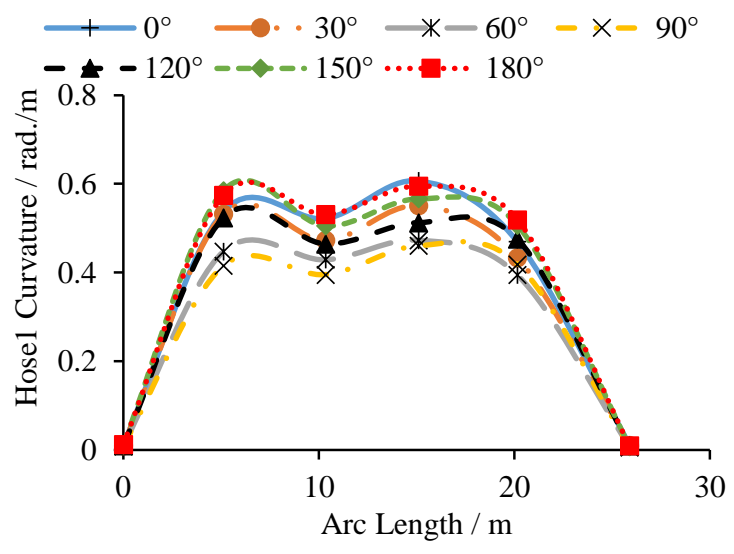

(b) Curvature for Hose1 without hose hydrodynamic load

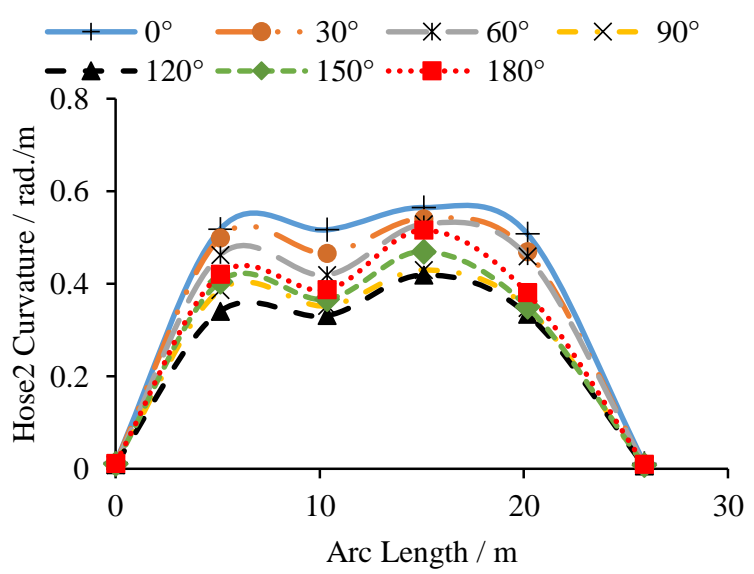

(d) Curvature for Hose2 without hose hydrodynamic load 


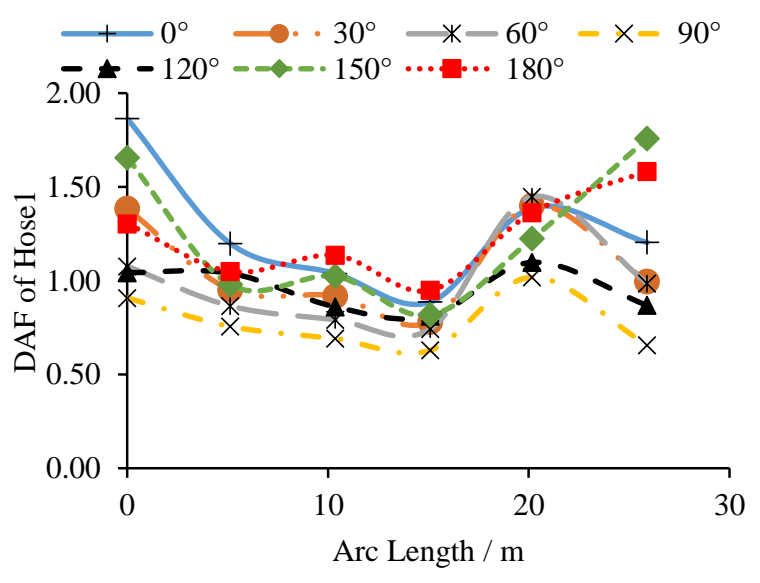

(e) Hose1 Curvature $D A F_{\text {Hose }}$

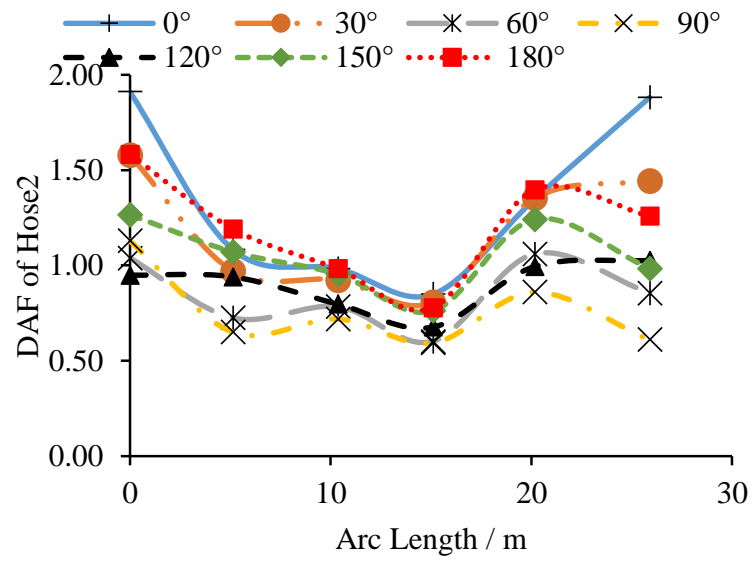

(f) Hose2 Curvature $D A F_{\text {Hose }}$

Figure 14 Effect of hose hydrodynamic load on curvature distribution along hose arc length

\section{Conclusion}

The effects of wave-induced response of floating CALM buoys on the load combination of submarine hose systems have been studied. Hydrodynamic models are developed though ANSYS AQWA to determine RAOs of the buoy. By incorporating the RAOs and key environmental, geometric and material properties, dynamic models on the CALM buoy with hose in Chinese-lantern configuration were established and validated.

A series of parametric studies were conducted by varying the flow angle. Effects of the flow angle and hose hydrodynamic loads on the structural response of the hose were studied in terms of bending moment, effective tension and curvature. The distributions of bending and tension along hose arc lengths were analysed and the influence of enhanced flexural stiffness at both top connections and the bottom touch down areas was discussed. It was observed that the curvature of the hose string at the ends was minimal, because of the stiffness of the reinforced hose end section, as shown in Table 1.

Models with $0^{\circ}$ or $180^{\circ}$ flow angle generally predicted greater bending moments, effective tension and curvatures than those with $90^{\circ}$ flow angle. The effects of the hose hydromantic loads on the structural response of the hose are associated with flow angles. The bending moments, effective tensions and curvatures in the simulations with inline-flow $\left(0^{\circ}\right.$ or $\left.180^{\circ}\right)$ and cross-flow $\left(90^{\circ}\right)$ are increased and reduced, respectively, if the hose hydromantic loads are considered. A guidance value of $D A F_{\text {hose }} 2.0$ to consider the hose hydromantic effects on the hose structural performance has been suggested accordingly. 


\section{Conflict of Interest}

There is no conflict of interest on this research work. We are grateful to SOFEC and EMSTEC for the permissions granted to the authors to use the images of Shell's Malampaya CALM buoy and examples of submarine hoses respectively.

\section{Acknowledgement}

The authors wish to acknowledge the financial support of the Engineering Department of Lancaster University, UK and Niger Delta Development Commission (NDDC) Nigeria. The research reported in this paper is part of the Project 51879143 supported by the National Natural Science Foundation of China (NSFC). The financial support is highly appreciated. The authors also acknowledge Dr Agbomerie Charles Odijie, of Dunlop Oil and Marine - a Subsidiary of ContiTech of Continental AG, for his technical support.

\section{References}

ABCNews, 2005. Accident prompts Navy to replace submarine hoses. Australian Broadcasting Corporation, p.1. Available at: http://www.abc.net.au/news/2005-08-03/accident-prompts-navyto-replace-submarine-hoses/2072338.

ABS, 2014. Rules For Building And Classing - Single Point Moorings, New York, USA: American Bureau of Shipping.

Amaechi, C.V. et al., 2018. Composite Risers for Deep Waters Using a Numerical Modelling Approach. Composite Structures.

Amaechi, C.V. \& Ye, J., 2017. A numerical modeling approach to composite risers for deep waters. In International Conference on Composite Structures (ICCS20) Proceedings. Paris, France: Societa Editrice Esculapo.

ANSYS, 2017a. ANSYS Aqwa Theory Manual, Release 18.2, Canonsburg, USA: ANSYS Inc.

ANSYS, 2017b. ANSYS Aqwa User's Manual, Release 18.2, Canonsburg, USA: ANSYS Inc.

ANSYS, 2017c. ANSYS Meshing User's Guide, Release 18.2, Canonsburg, USA: ANSYS Inc.

Bai, Y. \& Bai, Q., 2005. Subsea Pipelines and Risers 1st ed., Oxford, UK: Elsevier.

Barltrop, N.D.P., 1998. Floating Structures: A guide for design and analysis- Volume 2, Herefordshire, UK: Oilfield Publications Limited (OPL).

Barltrop, N.D.P. \& Adams, A.J., 1991. Dynamics of fixed marine structures 3rd Ed., Oxford, UK: Butterworth Heinemann.

Bense, M.P., 2011. Hydrodynamic Analysis of the Installation of a Gravity Based Foundation of Offshore Wind Turbine Generators. Bachelor Thesis. Technical University Berlin - Institute of Land and Maritime Transport.

Berhault, C. et al., 2004. Investigations on Hydrodynamic and Mechanical Coupling Effects for Deepwater Offloading Buoy. In International Offshore and Polar Engineering Conference. Toulon, France: ISOPE, pp. 374-379.

Bishop, R.E.D. \& Price, W.G., 2005. Hydroelasticity of ships, New York, USA: Cambridge 
University Press.

Bluewater, 2009. Buoyed Up: The future of tanker loading/offloading operations, Amsterdam, The Netherlands: Bluewater Energy Services.

Brebbia, C.A. \& Walker, S., 1979. Dynamic Analysis of Offshore Structures 1st Ed., London, UK: Newnes-Butterworth \& Co. Publishers Ltd.

Chakrabarti, S.K., 2005. Handbook of Offshore Engineering - Volume 1, Oxford, UK: Elsevier.

Chakrabarti, S.K., 2001. Hydrodynamics of offshore structures Reprint., Southampton, UK: WIT Press.

Chandrasekaran, S., 2015. Dynamic Analysis and Design of Offshore Structures 1st Ed., India: Springer.

Cozijn, H., Uittenbogaard, R. \& Brake, E. Ter, 2005. Heave, Roll and Pitch Damping of a Deepwater CALM Buoy with a Skirt. In International Society of Offshore and Polar Engineering Conference Proceedings. Seoul, Korea: ISOPE, pp. 388-395.

Cozijn, J.L. \& Bunnik, T.H.J., 2004. Coupled Mooring Analysis for a Deep water CALM Buoy; OMAE2004-51370. In International Conference on Offshore Mechanics and Arctic Engineering (OMAE) Proceedings. Vancouver, British Columbia, Canada: ASME, pp. 1-11.

Cunff, C. Le et al., 2007. Derivation of CALM Buoy coupled motion RAOs in Frequency Domain and Experimental Validation. In International Society of Offshore and Polar Engineering Conference Proceedings. Lisbon, Portugal: ISOPE, pp. 1-8.

Decheng, W., Yingzhong, L. \& Guoping, M., 1996. The interactions between wave-currents and offshore structures with consideration of fluid viscosity. Acta Mechanica Sinica, 12(4).

DNVGL, 2015. DNVGL-OS-E403 Offshore loading buoys, Oslo, Norway: Det Norske Veritas \& Germanischer Lloyd.

DNVGL, 2017. DNVGL-RP-F205 Global performance analysis of deepwater floating structures, Oslo, Norway: Det Norske Veritas \& Germanischer Lloyd.

Duggal, A. \& Ryu, S., 2005. The dynamics of deepwater offloading buoys. In WIT Transactions on The Built Environment. Singapore: WIT Press.

EMSTEC, 2016. EMSTEC Loading \& Discharge Hoses for Offshore Moorings, Rosengarten: EMSTEC.

Faltinsen, O.M., 1990. Sea Loads on Ships and Offshore Structures 1995 Repri., Cambridge, UK: Cambridge University Press.

Hasselmann, K. et al., 1973. Measurements of wind-wave growth and swell decay during the Joint North Sea Wave Project (JONSWAP). Ergänzungsheft zur Deutsche Hydrographische Zeitschrift; Ergänzungsheft; Reihe A, 12(80).

Irvine, H.M., 1981. Cable structures, USA: MIT Press.

Kang, Y. et al., 2014. Coupled analysis of FPSO and CALM buoy offloading system in West Africa. In Proceedings of the International Conference on Offshore Mechanics and Arctic Engineering OMAE2014-23118. California, USA: ASME.

Morison, J.R. et al., 1950. The Force Exerted by Surface Waves on Piles. Petroleum Transactions, AIME, 189, pp.149-154.

MSF, 2013. Guidelines for offshore marine operations (GOMO), London, UK: Marine Safety Forum (MSF). Available at: http://www.g-omo.info/wp-content/uploads/2016/06/201311GOMOfinal.pdf. 
Newman, J.N., 1977. Marine Hydrodynamics 1999 Repri., London, UK: MIT Press.

Newman, J.N. \& Lee, C.-H., 2002. Boundary-Element Methods in Offshore Structure Analysis. Journal of Offshore Mechanics and Arctic Engineering, 124(May 2002), pp.81-89.

O’Donoghue, T. \& Halliwell, A.R., 1990. Vertical bending moments and axial forces in a floating marine hose-string. Engineering Structures, 12(4), pp.124-133.

O'Sullivan, M., 2003. Predicting interactive effects of CALM buoys with deepwater offloading systems. Offshore Magazine, 63(1).

O’Sullivan, M., 2002. West of Africa CALM Buoy Offloading Systems. MCS Kenny Offshore Article. Available at: http://www.mcskenny.com/downloads/Software - Offshore Article.pdf.

OCIMF, 2009. Guide to Manufacturing and Purchasing Hoses for Offshore Moorings (GMPHOM), Livingstone, UK: Witherby Seamanship International Ltd.

Odijie, A.C., 2016. Design of paired column semisubmersible hull. PhD Thesis. Lancaster University, Lancaster, UK.

Odijie, A.C., Quayle, S. \& Ye, J., 2017. Wave induced stress profile on a paired column semisubmersible hull formation for column reinforcement. Engineering Structures, 143(April), pp.77-90. Available at: http://dx.doi.org/10.1016/j.engstruct.2017.04.013.

Odijie, A.C., Wang, F. \& Ye, J., 2017. A review of floating semisubmersible hull systems: Column stabilized unit. Ocean Engineering, 144(October 2016), pp.191-202. Available at: https://doi.org/10.1016/j.oceaneng.2017.08.020.

Oil\&GasUK, 2014. Tandem Loading Guidelines, Issue 3, London, UK: Oil \& Gas UK. Available at: http://www.marinesafetyforum.org/images/Tandem_Loading_Guidelines_Issue 3 Nov 14.pdf.

Orcina, 2014. OrcaFlex Manual, Version 9.8a, Ulverton, Cumbria, UK: Orcina Ltd. Available at: https://www.orcina.com/SoftwareProducts/OrcaFlex/Documentation/index.php.

Petrone, C., Oliveto, N.D. \& Sivaselvan, M. V., 2015. Dynamic Analysis of Mooring Cables with Application to Floating Offshore Wind Turbines. Journal of Engineering Mechanics, 142(3), pp.1-12.

Quéau, L.M., Kimiaei, M. \& Randolph, M.F., 2015. Approximation of the maximum dynamic stress range in steel catenary risers using artificial neural networks. Engineering Structures, 92, pp.172-185.

Quéau, L.M., Kimiaei, M. \& Randolph, M.F., 2011. Dynamic Amplification Factors for Response Analysis of Steel Catenary Risers at Touch Down Areas. In International Conference on Offshore and Polar Engineering (ISOPE) Proceedings. Maui, Hawaii, USA: ISOPE, pp. 1-5.

Roveri, F.E., Volnei, Luís Sagrilo, S. \& Cicilia, F.B., 2002. A Case Study on the Evaluation of Floating Hose Forces in a C.A.L.M. System. In Internation Offshore and Polar Engineering Conference. Kitakyushu, Japan,: ISOPE, pp. 190-197.

Ryu, S. et al., 2006. Prediction of Deepwater Oil Offloading Buoy Response and Experimental Validation. International Journal of Offshore and Polar Engineering, 16(3), pp.1-7.

Sagrilo, L.V.S. et al., 2002. A coupled approach for dynamic analysis of CALM systems. Applied Ocean Research, 24, pp.47-58.

Salem, A.G. et al., 2012. Linearization of Quadratic Drag to Estimate CALM Buoy Pitch Motion in Frequency-Domain and Experimental validation. Journal of Offshore Mechanics and Arctic Engineering, 134(11305-1), pp.3-8.

Santala, M.J. \& Wang, H., 2016. Component Approach for Confident Predications of Deepwater 
CALM Buoy Coupled Motions - Part 2: Analytical Implementation -OMAE2005-67140. , (Omae 2005), pp.1-9.

Sarpkaya, T., 2014. Wave forces on offshore structures 1st ed., New York, USA: Cambridge University Press.

SOFEC, 2017. Malampaya CALM - Philippines. Marine Terminals - CALM Buoys, p.1. Available at: http://www.sofec.com/productItem.asp?intcategoryName=Marine Terminals\&intsubCat=CALM Buoys\&intproductID=Malampaya2 [Accessed February 20, 2018].

Sun, L. et al., 2015. Motion response analysis of FPSO's CALM buoy offloading system OMAE2015-41725. In International Conference on Ocean, Offshore and Arctic Engineering. St. John's, Newfoundland, Canada: ASME, pp. 1-7.

Trelleborg, 2016. CALM Buoy /Chinese Lantern Configuration. Trelleborg. Available at: http://www.trelleborg.com/en/fluidhandling/products--and--solutions/offshore--oil--and--gas-solutions/oil/calm--buoy_chinese--lantern--configuration.

Wall, M. et al., 2001. Failure Modes, Reliability and Integrity of Floating Storage Unit (FPSO, FSU) Turret and Swivel Systems, Abingdon, UK: HSE Books. Available at: http://www.hse.gov.uk/research/otohtm/2001/oto01073.htm.

Wang, D. \& Sun, S., 2015. Study of the Radiation Problem for a CALM Buoy with Skirt. Ship Building of China, 56(1), pp.95-101.

Wang, F. et al., 2017. Development and sea trial of real-time offshore pipeline installation monitoring system. Ocean Engineering, (February), pp.1-9. Available at: https://doi.org/10.1016/j.oceaneng.2017.09.016.

Wang, F., 2018. Effective design of submarine pipe-in-pipe using Finite Element Analysis. Ocean Engineering, 153, pp.23-32.

Wang, F. \& Han, L., 2019. Analytical behaviour of carbon steel-concrete-stainless steel double skin tube (DST) used in submarine pipeline structure. Marine Structures, 63, pp.99-116.

Wichers, I.J., 2013. Guide to Single Point Moorings, Houston, USA: WMooring Inc.

Williams, N.A. \& McDougal, W.G., 2013. Experimental Validation Of A New Shallow Water Calm Buoy Design - OMAE2013-11392. In International Conference on Ocean, Offshore and Arctic Engineering. Nantes, France: ASME, pp. 1-6.

Wilson, J.F., 2003. Dynamics of offshore structures 2nd ed., New Jersey, USA: John Wiley and Sons.

Ye, J., 1988. A new approach for the bending problem of shallow shell by the boundary element method. Applied Mathematical Modelling, 12(5), pp.467-470.

Ye, J., 2016. Structural and Stress Analysis: Theories, tutorials and examples Second., New York, USA: CRC Pres.

Yokohama, 2016. Seaflex Yokohama Offshore loading \& discharge hose, Hiratsuka City, Japan: The Yokohama Rubber Co. Ltd.

Ziccardi, J.J. \& Robbins, H.J., 1970. Selection of Hose Systems for SPM Tanker Terminals. In Offshore Technology Conference Proceeding -OTC 1152. Dallas, Texas, USA: OnePetro, pp. 83-94. 
APPENDIX:

$$
[\boldsymbol{M}]=\left[\begin{array}{cccccc}
m & 0 & 0 & 0 & m z_{g} & -m y_{g} \\
0 & m & 0 & -m z_{g} & 0 & -m x_{g} \\
0 & 0 & m & m y_{g} & -m x_{g} & 0 \\
0 & -m z_{g} & m y_{g} & I_{44} & I_{45} & I_{46} \\
m z_{g} & 0 & -m x_{g} & I_{54} & I_{55} & I_{56} \\
-m y_{g} & m x_{g} & 0 & I_{64} & I_{65} & I_{66}
\end{array}\right]
$$

The mass matrix, $[\mathbf{M}]$ in Equation (1) is given by the matrix in Equation (7), where $\mathrm{m}$ is the mass parameter of the buoy, $I_{44}$ is the roll moment of inertia of the buoy, $I_{55}$ is the pitch moment of inertia of the buoy, $I_{66}$ is the yaw moment of inertia of the buoy, $x_{g}$ is the mass of the buoy about the centre of gravity in x-plane, $y_{g}$ is the mass of the buoy about the centre of gravity in x-plane, $z_{g}$ is the mass of the buoy about the centre of gravity in $\mathrm{x}$-plane. Further formulations on the mass matrix are in literature (Odijie 2016; Faltinsen 1990; Newman 1977).

The stiffness matrix, [K] in Equation (1) is given by Equation (8), where $K_{33}$ is the stiffness in heave degree of freedom, $K_{44}$ is the stiffness in roll degree of freedom and $K_{55}$ is the stiffness in pitch degree of freedom. The stiffness values of zero as recorded for surge, sway and yaw in columns 1, 2 and 6 in the matrix to represent the hydrostatic stiffness of the free floating buoy, on the horizontal plane.

$$
[\boldsymbol{K}]=\left[\begin{array}{cccccc}
0 & 0 & 0 & 0 & 0 & 0 \\
0 & 0 & 0 & 0 & 0 & 0 \\
0 & 0 & K_{33} & K_{34} & K_{35} & 0 \\
0 & 0 & K_{43} & K_{44} & K_{45} & 0 \\
0 & 0 & K_{53} & K_{54} & K_{55} & 0 \\
0 & 0 & 0 & 0 & 0 & 0
\end{array}\right]
$$

The hydrodynamic analysis considers the buoy as a rigid body. For a free floating CALM buoy system, the stiffness values $K_{46}$ and $K_{56}$ are equal to zero when there is no mooring line, submarine hose or any riser system. The 6 X 6 matrix is used to obtain Equation (9), which is the resultant 3 X 3 matrix.

$$
[\boldsymbol{K}]=\left[\begin{array}{lll}
K_{33} & K_{34} & K_{35} \\
K_{43} & K_{44} & K_{45} \\
K_{53} & K_{54} & K_{55}
\end{array}\right]
$$

The damping matrix, [C] in Equation (1) is given by the matrix in Equation (10) for the buoy when wave load RAOs are considered, where $C_{11}$ is the surge damping, $C_{33}$ is the heave damping, $C_{55}$ is the pitch damping, $C_{15}$ is the coupled surge pitch damping.

$$
[\boldsymbol{C}]=\left[\begin{array}{cccccc}
C_{11} & 0 & 0 & 0 & C_{15} & 0 \\
0 & C_{22} & 0 & -C_{24} & 0 & 0 \\
0 & 0 & C_{33} & 0 & 0 & 0 \\
0 & -C_{42} & 0 & C_{44} & 0 & 0 \\
C_{15} & 0 & 0 & 0 & C_{55} & 0 \\
0 & 0 & 0 & 0 & 0 & 0
\end{array}\right]
$$

The displacement vector, $\{\mathbf{x}\}$ in Equation (1) is given by the matrix in Equation (11), where $u$ is the displacement in $\mathrm{x}$-axis, $\mathrm{v}$ is displacement in $\mathrm{y}$-axis, $\mathrm{w}$ is displacement in $\mathrm{z}$-axis, $\Theta_{\mathrm{xx}}$ is the rotation along the $x$-plane, $\Theta_{y y}$ is the rotation along the y-plane and $\Theta_{z z}$ is the rotation along the z-plane.

$$
\{x\}=\left[\begin{array}{c}
u \\
v \\
w \\
\theta_{x x} \\
\theta_{y y} \\
\theta_{z z}
\end{array}\right]
$$

